\title{
Four-Repeat Tauopathies: Current Management and Future Treatments
}

\author{
Lawren VandeVrede $^{1}$ (D) Peter A. Ljubenkov ${ }^{1} \cdot$ Julio C. Rojas $^{1} \cdot$ Ariane E. Welch $^{1} \cdot$ Adam L. Boxer $^{1}$ \\ Published online: 16 July 2020 \\ (C) The American Society for Experimental NeuroTherapeutics, Inc. 2020
}

\begin{abstract}
Four-repeat tauopathies are a neurodegenerative disease characterized by brain parenchymal accumulation of a specific isoform of the protein tau, which gives rise to a wide breadth of clinical syndromes encompassing diverse symptomatology, with the most common syndromes being progressive supranuclear palsy-Richardson's and corticobasal syndrome. Despite the lack of effective disease-modifying therapies, targeted treatment of symptoms can improve quality of life for patients with 4-repeat tauopathies. However, managing these symptoms can be a daunting task, even for those familiar with the diseases, as they span motor, sensory, cognitive, affective, autonomic, and behavioral domains. This review describes current approaches to symptomatic management of common clinical symptoms in 4-repeat tauopathies with a focus on practical patient management, including pharmacologic and nonpharmacologic strategies, and concludes with a discussion of the history and future of disease-modifying therapeutics and clinical trials in this population.
\end{abstract}

Keywords 4R-tauopathy (4R-tau) · progressive supranuclear palsy (PSP) · Richardson's syndrome (PSP-RS) · corticobasal syndrome (CBS) · corticobasal degeneration (CBD) · atypical parkinsonism

\section{Introduction}

Aggregation of tau is the key pathologic feature in a range of neurodegenerative diseases, collectively termed tauopathies [1]. The term "tau" refers to the protein product of the microtubule-associated protein tau gene (MAPT), and the number of spliced copies of the microtubule binding repeat (MTBR) domain determines whether the tau is a 3-repeat (3R) or a 4-repeat (4R) isoform [2]. In the healthy adult brain, 3Rtau and 4R-tau are found in equal numbers, but pathological conditions may give rise to abnormal expression and aggregation of 4R-tau [3, 4]. As defined by neuropathology, 4R tauopathies are considered a subtype of frontotemporal lobar degeneration due to tau (FTLD-tau), and they are classified according to the morphologic appearance, histologic localization, and anatomical distribution of primarily 4R-tau aggregates into progressive supranuclear palsy (PSP), corticobasal degeneration (CBD), argyrophilic grain disease (AGD),

Lawren VandeVrede

Lawren.VandeVrede@ucsf.edu

1 Memory and Aging Center, Department of Neurology, University of California San Francisco, San Francisco, California, USA globular glial tauopathy (GGT), and FTLD-tau due to MAPT mutation [5-7].

The accumulations of insoluble, predominantly $4 \mathrm{R}$-tau protein tend to affect characteristic brain regions and follow a typical anatomical pattern of deposition and spread, leading to diverse but well-defined clinical syndromes (Table 1), with the most widely known being progressive supranuclear palsy-Richardson's syndrome (PSP-RS), marked by early falls because of postural instability and progressive ocular motor dysfunction, and corticobasal syndrome (CBS), defined by asymmetric motor features (e.g., akinesia, rigidity, dystonia, myoclonus) and higher cortical signs (e.g., apraxia, cortical sensory deficits, alien limb) $[8,9]$. 4R-tauopathies, however, can also present clinically with parkinsonism similar to Parkinson's disease, pure akinesia with gait freezing (PAGF), primary lateral sclerosis (PLS), the nonfluent variant of primary progressive aphasia (nfvPPA), the behavioral variant of frontotemporal dementia (bvFTD), and an amnestic syndrome similar to Alzheimer's dementia [8-11]. In later stages of the disease, mixed features of many syndromes may be present.

The correlation of phenotypic clinical presentation and underlying neuropathological entity is challenging in $4 \mathrm{R}$ - 
Table 1 Histopathologic subtypes of 4R-tauopathy and presenting clinical phenotypes

\begin{tabular}{|c|c|}
\hline $\begin{array}{l}\text { 4R-Tau } \\
\text { pathology }\end{array}$ & Associated clinical syndromes \\
\hline $\begin{array}{l}\text { Progressive supranuclear } \\
\text { palsy (PSP) }\end{array}$ & $\begin{array}{l}\text { Progressive supranuclear palsy-Richardson's syndrome (PSP-RS), } \\
\text { Corticobasal syndrome (CBS), } \\
\text { Parkinsonism similar to Parkinson's disease, nonfluent variant of primary } \\
\text { progressive aphasia (nfvPPA), behavioral variant of frontotemporal dementia } \\
\text { (bvFTD), } \\
\text { Primary akinesia with gait freezing (PAGF), } \\
\text { Primary lateral sclerosis (PLS) }\end{array}$ \\
\hline $\begin{array}{l}\text { Corticobasal degeneration } \\
\qquad(\mathrm{CBD})\end{array}$ & $\begin{array}{l}\text { Corticobasal syndrome (CBS), } \\
\text { Progressive supranuclear palsy-Richardson's syndrome (PSP-RS), } \\
\text { Nonfluent variant of primary progressive aphasia (nfvPPA), } \\
\text { Behavioral variant frontotemporal dementia (bvFTD), } \\
\text { Amnestic syndrome similar to Alzheimer's dementia }\end{array}$ \\
\hline $\begin{array}{l}\text { Argyrophilic grain disease } \\
\qquad(\mathrm{AGD})\end{array}$ & $\begin{array}{l}\text { Amnestic syndrome similar to Alzheimer's dementia, } \\
\text { Behavioral variant of frontotemporal dementia (bvFTD) }\end{array}$ \\
\hline $\begin{array}{l}\text { Globular glial tauopathy } \\
\text { (GGT) }\end{array}$ & $\begin{array}{l}\text { Wide variety of clinical phenotypes, commonly with behavioral symptoms, } \\
\text { atypical parkinsonism, and/or motor neuron disease (full description still de- } \\
\text { veloping) }\end{array}$ \\
\hline
\end{tabular}

tauopathies. A given neuropathological entity can have heterogeneous clinical presentations, and it is often difficult to predict the underlying pathology based on the clinical syndrome. Differentiation between 4R-tau neuropathological subtypes prior to autopsy has proven elusive, not only because of the overlap of symptomatology within the 4R-tauopathies but also because of overlap with clinical syndromes caused by neuropathologic protein aggregates seen in other neurodegenerative diseases, such as Alzheimer's or TAR DNA binding protein 43 (TDP-43) proteinopathies. As an example, one clinicopathologic study found that less than half of cases with a clinical diagnosis of corticobasal syndrome were found to be due to 4R-tauopathy (35\% CBD, 13\% PSP), and underlying CBD versus PSP could not be reliably differentiated based on clinical features alone [12].

Nevertheless, the 2017 Movement Disorder Society PSP diagnostic criteria identified 4 functional domains commonly seen in PSP syndromes (oculomotor dysfunction, postural instability, akinesia, and cognitive dysfunction) that have been proposed as clinical predictors of underlying PSP pathology [9]. These criteria have a high specificity for predicting PSP pathology, especially in the presence of ocular motor dysfunction, but sensitivity is low in early stages of the illness [13]. Similarly, 5 clinical phenotypes account for over $85 \%$ of patients with CBD pathology, and 4 of them comprise proposed clinical diagnostic criteria for CBD [14]. Because clinical CBD syndromes extensively overlap with PSP syndromes, for the purpose of this review, we will consider 4R-tauopathies as one disease spectrum and discuss treatment without regard to specific diagnosis [15].
Despite ongoing efforts in clinical trials, there are no FDAapproved treatments that reverse, stop, or delay progression of 4R-tauopathies, and current management is focused on ameliorating symptoms, maintaining function, and maximizing quality of life. As the disease progresses, symptoms can arise in multiple domains, with motor features often prominent, and the many options that are available to manage these symptoms can easily be overlooked in the routine care of 4R-tauopathy patients (Table 2). Therefore, whereas several excellent comprehensive reviews of 4R-tauopathy are available [16-19], herein, we will focus on the practical clinical management of 4R-tauopathies for providers, including pharmacologic and nonpharmacologic approaches. Finally, we will conclude with a discussion of past and current clinical trial efforts to find novel disease-modifying therapeutics in this population with great unmet medical need.

\section{Current Symptomatic Management}

\section{Motor Symptoms}

\section{Bradykinesia/Rigidity}

In line with pathological evidence of neuronal loss in the substantia nigra [20], patients with 4R-tauopathy often show features of an akinetic and rigid parkinsonism, but the response to dopamine replacement is typically modest and short-lived, and a prominent and sustained response is exclusionary for a diagnosis of CBD [14, 21, 22]. However, phenotypes of PSP with predominant parkinsonism (PSP-P) 
Table 2 Symptomatic management of 4R-tauopathy

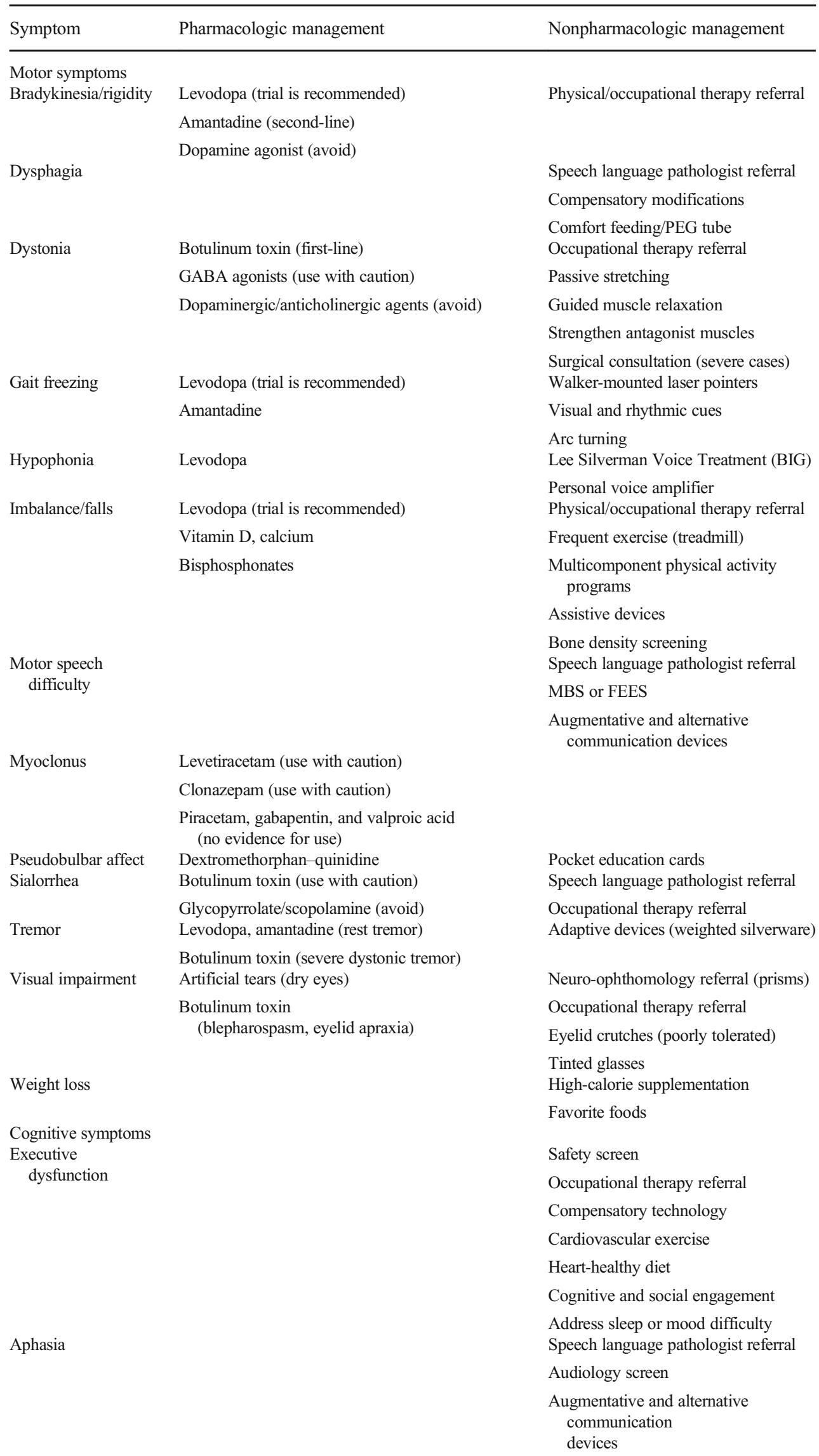


Table 2 (continued)

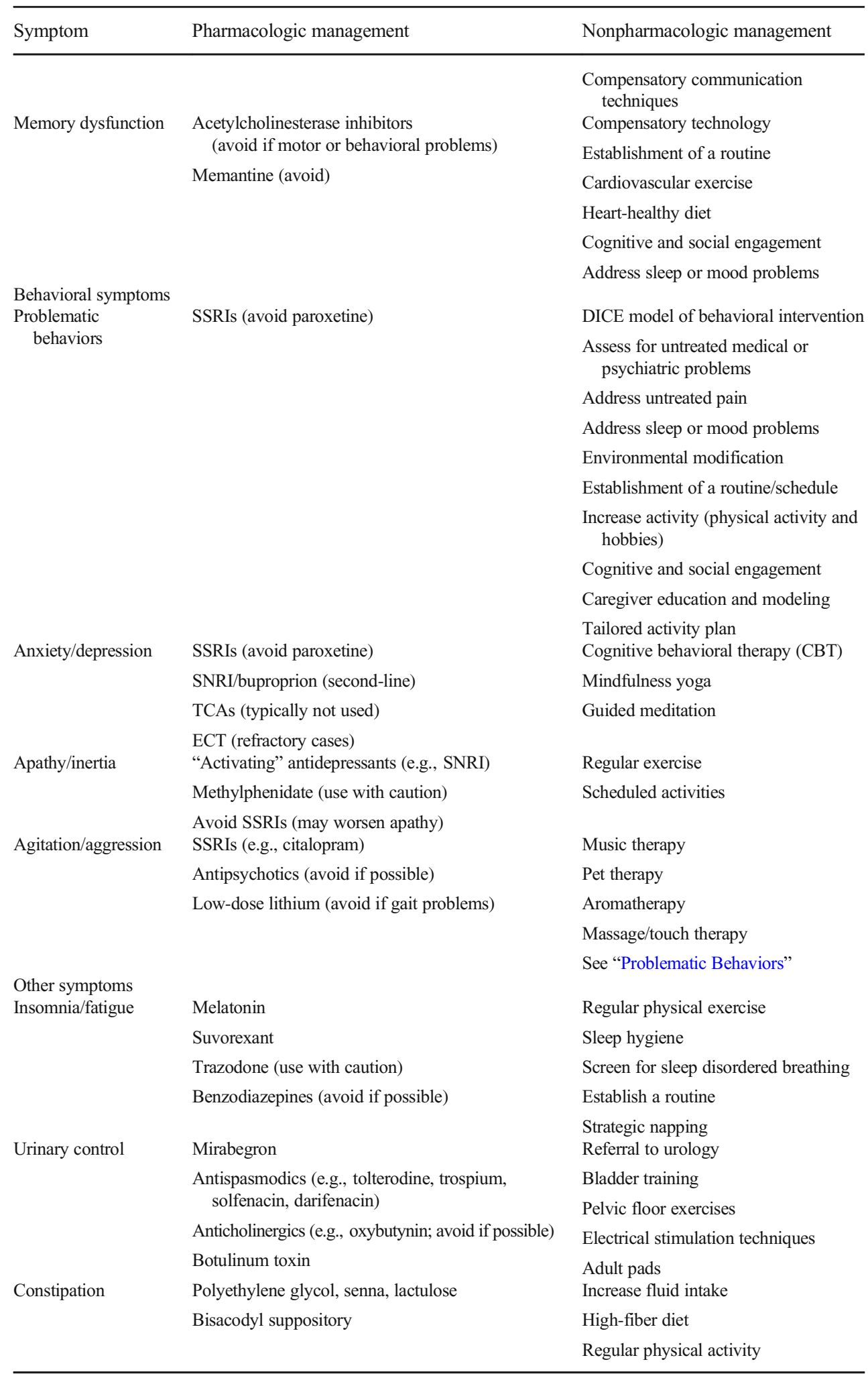

may show a more measurable and sustained benefit from levodopa, and a cautious dose-escalation trial up to 800 to $1200 \mathrm{mg} /$ day is recommended, both for diagnostic and therapeutic considerations, unless limited by other symptomatology [18]. Sudden discontinuation of dopaminergic therapy should be avoided, but if side effects such as visual hallucinations, dystonia, or dyskinesias arise, cessation is recommended [23]. 
Amantadine is another therapeutic often employed to reduce bradykinesia, and although a clinical response is typically seen only in a fraction of cases [24], some authors report effects beyond reducing akinesia and rigidity and suggest improvement in alertness, motivation, and overall function $[25$, $26]$. Dopamine receptor agonists are used less frequently given limited evidence for efficacy and the possibility of developing compulsive behaviors if frontostriatal involvement is present [27-29].

Early involvement of ancillary health fields such as physical therapy and occupational therapy is also recommended to preserve functional independence, and a randomized clinical trial provided strong evidence for this approach by demonstrating functional clinically meaningful improvements on the PSP rating scale using an intensive, aerobic, multidisciplinary, motor-cognitive, and goal-based rehabilitation program in 24 patients with PSP-RS [30].

\section{Dysphagia}

Aspiration pneumonia is the leading cause of death in PSP-RS [31], and progressive dysphagia is a key symptom leading to morbidity and mortality in 4R-tauopathies, which may be worsened if behavioral symptoms such as impulsive and rapid eating are present. Vigilance for swallowing symptoms is recommended even in early stages, and some authors recommend routine swallow evaluation every 6 months [18]. A measured approach to dysphagia treatment should carefully weigh reduction in aspiration risk alongside considerations of hydration, quality of life, preferences for end-of-life care, and respect for familial and cultural values.

A referral to a speech-language pathologist (SLP) for an instrumental swallow evaluation such as a modified barium swallow (MBS) exam or fiberoptic endoscopic evaluation of swallowing (FEES) can detect overt or silent aspiration, which can lead to compensatory modifications including change in bolus size, texture, and presentation rate; changes in head posture; education on safe swallowing strategies; tactile and/ or verbal cuing; adaptations to mealtime equipment; and assisted hand feeding as indicated [32-35]. Rehabilitative approaches include swallowing exercises, expiratory muscle strength training (EMST), Lee Silverman Voice Training (LSVT), transcutaneous neuromuscular electrical stimulation (NMES) with or without EMG biofeedback, and various neuromodulation techniques [36-40]. However, due to insufficient or low-quality evidence to determine the safety and efficacy of many of these interventions in neurodegenerative dysphagia, there is a particular need for more research in this population.

If dysphagia is accompanied by weight loss, referral to a dietitian can help ensure appropriate caloric and nutritional intake, and offering high-calorie nutritional supplements and favorite foods is often a successful strategy to maintain weight. Placement of a percutaneous endoscopic gastrostomy (PEG) tube is a challenging and an ethically fraught decision in neurodegenerative disease, and early discussion of this issue should guide later management. However, it should be stressed that the risk of aspiration remains after PEG placement, as it does not prevent the aspiration of gastric contents and saliva, nor does it preclude ongoing oral intake, and in the cases in which dysphagia is accompanied by severe akinesia and rigidity, PEG placement can lead to the prolongation of a very poor quality of life and a difficult decision as to when to withdraw feeding for patients' families. Comfort-based latestage dysphagia management centers around the identification of feeding strategies for pleasure, accepting that aspiration may occur [41].

\section{Dystonia}

Increased tone can be the most prominent feature in 4Rtauopathies, especially when presenting as corticobasal syndrome, in which dystonia is typically asymmetric and may affect an upper/lower extremity or present as cervical dystonia or blepharospasm [42]. Pain as a result of dystonia is sometimes considerable and disabling, and general pharmacologic and nonpharmacologic strategies to manage pain should be employed, in collaboration with a chronic pain or palliative care specialist when necessary.

Local paralysis of focal dystonic muscles by botulinum toxin is the mainstay of treatment for dystonia, with resultant improvement in dystonic posturing and pain reported in a subset of patients [29, 43-45]. Oral pharmacologic strategies for dystonia include muscle relaxants working through GABA agonism (e.g., clonazepam, tizanidine, baclofen), though treatment effect is often disappointing, and systemic side effects such as sedation and increased fall risk limit their utility $[18,29]$. Dopaminergic (e.g., levodopa) and anticholinergic agents (e.g., benztropine, trihexyphenidyl) have not been found to be effective in treating dystonia, and anticholinergics should be avoided because of worsening cognition and mood $[29,46]$.

Controlled studies are lacking to support the use of dystonia-targeted physical therapy intervention in 4Rtauopathies, but interventions such as passive stretching to mitigate contractures, guided muscle relaxation techniques, and strengthening of antagonist muscles may be beneficial and pose limited risk to the patient $[47,48]$. Use of modified assistive devices may also support function, whereas severe limb deformities from dystonia may require consultation with plastic surgery.

\section{Imbalance/Falls}

Postural instability and falls are central to the diagnostic criteria for Richardson's syndrome, and decreased regional 
glucose metabolism during locomotion has been observed in subcortical and cortical locomotor centers in PSP, supporting dysfunction of these brain regions as central to the disease [49, 50]. In addition, 4R-tauopathy patients may also have axial rigidity, dystonia, visual impairment, and impulsivity, which can exacerbate imbalance and lead to a high fall risk early in the disease [50, 51].

Frequent exercise with careful monitoring to avoid injury from falls, including treadmill exercise, is beneficial for preserving balance and reducing falls in PSP-RS [30, 52, 53], and in our experience, many of the structured multicomponent physical activity programs studied in Parkinson's disease, which include tai chi, dance therapy, boxing training, and Feldenkrais-based exercise, can improve quality of life in 4R-tauopathy patients [54-58]. For patients with gait freezing, use of ancillary devices such as walker-mounted laser pointers, visual and rhythmic cues, and arc turning can be employed [18]. In a single case report, transcranial magnetic stimulation (TMS) reduced freezing and falling; however, this is still considered experimental and currently the approach cannot be recommended [59].

Weighted walkers (such as the U-Step walker) in combination with physical therapy have been shown in case reports to prevent falls and preserve independence [53], and assistive devices such as wheelchairs and mobility scooters should be introduced before injurious falls become frequent. Also, given the high risk of injurious falls including bone fracture [51], age-appropriate bone density screening should be considered, with initiation of calcium, vitamin $\mathrm{D}$, and bisphosphonates if indicated.

\section{Involuntary Movements (Tremor/Myoclonus)}

Tremor in 4R-tauopathies can be resting, postural, kinetic, dystonic, or mixed, but tremor typically occurs much less frequently than in diseases such as idiopathic Parkinson's disease, and data on pharmacologic efficacy specifically for tremor in this population are limited [60,61]. As with standard treatment of tremor, a careful review of medications for offending agents should be conducted prior to initiation of pharmacologic therapy. A trial of dopaminergic agents (e.g., levodopa, amantadine) for patients with disabling rest tremor is appropriate, and treatment of action tremor with typical agents may be considered. Botulinum toxin can be considered in advanced cases of dystonic tremor, and adaptive devices are available for a range of action tremors, including weighted and motion-canceling silverware.

Myoclonus, often triggered by motor or sensory stimulation, is commonly associated with CBS [62]. Pharmacologic treatment strategies include levetiracetam and clonazepam, though levetiracetam is associated with worsening behavioral changes, and the use of benzodiazepines is limited by sedation and increased fall risk [18,
63, 64]. Piracetam, gabapentin, and valproic acid have been proposed as second-line agents [63], though the evidence base for use in this cohort is poor.

\section{Motor Speech Difficulty and Voice Disorders}

Motor speech difficulty is common in 4R-tauopathies and can present either as focal or mixed dysarthrias, apraxia of speech, or hypophonia. Patients with PSP-RS most frequently present with a mixed dysarthrophonia characterized by hypokinetic and spastic features, with ataxic speech being less common [65-68]. Motor speech characteristics in CBS are less well described but include a spastic or hypokinetic dysarthria with or without apraxia of speech $[69,70]$. In the nonfluent variant of primary progressive aphasia (nfvPPA), apraxia of speech and a heterogenous range of dysarthrias are common.

Regardless, speech therapy is recommended with an SLP, giving early consideration to augmentative and alternative communication (AAC) aids (e.g., low- or high-technology pictographic boards, voice banking, and speech-generating devices) [71]. AAC is ideally implemented prior to the development of anarthria or significant cognitive impairments, involves the patient's communication partners, and adapts to the patient's motor, cognitive, visuospatial, and ecological needs over time [72]. Treatments that directly target speech articulation and intelligibility include overarticulation and rate modification [73-75].

For hypophonia, the Lee Silverman Voice Treatment (LSVT) program has been shown to reduce motor speech and voice symptoms in patients with PD, and can be considered in this population with or without use of a personal voice amplifier [76].

\section{Pseudobulbar Affect}

Pseudobulbar affect (PBA) is characterized by inappropriate, disproportionate, or uncontrollable laughing and/or crying, and the social impact and resultant embarrassment can lead to restriction of social activities and a lower quality of life [77]. Dextromethorphan-quinidine is FDA approved to treat PBA in a number of neurologic conditions, and efficacy has been demonstrated in clinical trials in dementia, stroke, traumatic brain injury, and ALS [78-80]. In our experience, dextromethorphan-quinidine is also effective at treating bulbar symptoms in PSP-RS. Careful questioning is often necessary to identify the presence of pseudobulbar symptoms, but subsequent patient and family education alone can reduce embarrassment and anxiety. Pocket or wallet-sized education cards can be carried and passed out in public to increase awareness of PBA, which may facilitate social engagement and acceptance. 


\section{Sialorrhea}

The mechanism of chronic excess saliva in 4R-tauopathies is unclear, but may be a result of impaired oral salivary clearance due to orobuccal apraxia or dysphagia. Anticholinergic agents like glycopyrrolate produce less CNS toxicity than scopolamine, the use of which should be avoided because of significant systemic adverse effects on cognition, gait, and balance [81]. Botulinum toxin injection to the salivary glands can reduce saliva production, but may worsen dysphagia [63]. SLPs or occupational therapists can be helpful in implementing techniques such as biofeedback or automatic cuing, whereas a dentist can help ensure good oral hygiene.

\section{Visual Impairment}

Ocular motor impairments frequently accompanied by diplopia are a core feature of PSP-RS, but may be seen in other 4Rtauopathies as the disease progresses. Other symptoms such as square wave jerks, blepharospasm, eyelid apraxia, dry eye syndrome, reduced blink rate, and photosensitivity may be present, and the resultant visual impairment may contribute to falls and impact daily life by causing difficulty with reading, eating, and maintaining appropriate social eye contact. Visuospatial processing impairment is less common, though may be present, particularly in CBS.

Botulinum toxin has been FDA approved for the treatment of blepharospasm since 1989, and many studies have reported that approximately $90 \%$ of patients will see a clinical benefit with this approach [82]. Botulinum toxin has also been employed to treat eyelid apraxia [83], and as with other applications of this agent, technical considerations regarding muscle selection should be done in consultation with an experienced provider. Eyelid "crutches" for the treatment of eyelid apraxia are typically poorly tolerated by patients.

Pharmacologic options for gaze palsy are limited, but intriguingly, short-lived motor improvement was seen after treatment with zolpidem in small trials and a case report, though sedation limits the utility of this benefit [84, 85]. Referral to a neuro-ophthalmologist or neuro-optometrist to be fitted for prisms is often the best option available to improve visual function. Finally, artificial tears are a safe and effective treatment for dry eyes, and tinted glasses may help with photosensitivity.

Occupational therapists are often an excellent resource for patients with visual impairment of any cause, and many creative strategies are available to improve visual function. Examples include ensuring appropriate home lighting, removing clutter, improving visual contrasts, and the use of tilted mirrors and assistive reading technology (e.g., bookstands, magnifying glasses, and audio books), or the simple use of an eye patch to eliminate diplopia.

\section{Cognitive Symptoms}

\section{Executive Dysfunction}

Cognitive impairment can occur even in motor-predominant syndromes, and subtle changes in executive function can often be uncovered with careful questioning and formal neuropsychological testing. If significant executive dysfunction is present, a thorough safety screen should be conducted that includes an assessment for medication mismanagement, financial risk and scams, home safety in the kitchen (e.g., use of stove), driving risk, and unsecured firearms.

Management of executive dysfunction includes implementing strategies such as environmental modifications (e.g., structured routine, minimizing distractors, simplifying tasks) and compensatory technology (e.g., daily planners, mobile devices), which may be facilitated through a referral to an occupational therapist [86]. General recommendations on lifestyle modifications for other dementias may apply in this population and are reasonable to consider. Typical interventions include increasing cardiovascular exercise, adopting a hearthealthy diet, ensuring adequate sleep and nutrition, and staying cognitively and socially engaged [87]. The use of medications for cognitive impairment typically employed for Alzheimer's disease (AD) is discussed under "Memory Dysfunction" below.

\section{Aphasia}

In patients with cortical language dysfunction, such as the agrammatism and loss of fluency seen in nfvPPA [11], ongoing management by an SLP is recommended. Standard SLP rehabilitative interventions initially target syntax and, as the disease progresses, include reading, spelling, and word finding, and a "Life Participation" approach aims to maximize functional communication and participation in desired life activities [88-90]. Given the high prevalence of hearing loss in elderly patients, and the association of hearing loss with dementia [91, 92], an audiology screening should also be considered.

Intriguingly, studies in nfvPPA suggest that videoimplemented script training (VISTA) may improve intelligibility, speech production and grammar in trained and/or untrained topics, and research is ongoing to better understand the efficacy of this intervention [93, 94]. Given access challenges to academic centers where specialized care is available, aphasia therapy over telehealth has also been demonstrated to be as effective as in person therapy in patients with primary progressive aphasia [95]. Finally, in limited studies, transcranial direct current stimulation (tDCS) has been shown to be safe and potentially effective [96, 97], and several current clinical trials are planned or underway to determine the utility of tDCS in patients with primary progressive aphasia. 
In addition to the provision of AAC devices (discussed in "Motor Speech Difficulty and Voice Disorders"), compensatory interventions for aphasia can train communication partners in adapting their communication style to facilitate their loved one's communication and comprehension [98, 99]. Basic principles include the following: [1)] eliminate distractions such as multiple speakers or background noise; [2)] establish attention and then speak face to face; [3)] keep sentences short and direct; [4)] stay on one topic at a time with frequent clarification and repetition; [5)] for patients with yes/ no confusion, frame questions to provide lexical options (e.g., "chicken or fish?"); [6)] use and encourage patients to use nonspeech modalities such as gestures, facial expressions, writing, drawing, and pointing at pictures; and [7)] be patient and allow enough time for a response.

\section{Memory Dysfunction}

The role of medications such as the acetylcholinesterase inhibitors (AChEI) typically employed in Alzheimer's disease is controversial in 4R-tauopathies. Cholinergic neuron loss has been observed in postmortem studies in PSP [100], so use of AChEIs in this population is biologically plausible, but in a randomized clinical trial of donepezil in 21 patients with PSPRS, a small positive effect on memory was more than offset by a dose-limiting worsening of motor symptoms, leading the authors to recommend against its use in this cohort [101]. Additionally, in patients presenting with frontal lobe impairments, AChEIs can worsen behavioral symptoms [102, 103]. A trial of AChEI may be justifiable if cognitive symptoms dominate the clinical picture without motor or behavioral features, as in amnestic presentations similar to AD.

Multiple studies of memantine in patients with frontotemporal dementias have shown no benefit or even worsening of cognition in some individuals [104-106], so routine use of this agent is not recommended. However, if AD biomarker studies (such as amyloid PET or CSF abeta/ tau) support $\mathrm{AD}$ as an underlying cause of $\mathrm{CBS}$, which may occur in up to $\sim 40 \%$ of cases, AChEI or memantine might be more reasonably considered. Nonpharmacological strategies employed in Alzheimer's disease are also useful in patients with memory impairment due to a 4R-tauopathy, including the use of a daily planner and mobile devices and establishing a daily routine.

\section{Behavioral Symptoms}

\section{Problematic Behaviors}

Typical behavioral changes in 4R-tauopathies are impulsivity and apathy, but disruptive behavioral changes can be a presenting or late feature [9, 12, 107], and behavioral impairment is the defining feature of bvFTD presentations, with diagnostic criteria that include disinhibition, apathy, loss of sympathy/empathy, unusual compulsions, and hyperorality (impulsive overeating) [108]. If present, these behaviors can cause substantial distress to the patient's family and loved ones, contributing to caregiver burden and burnout, and management of these behaviors is a frequent reason for referral to a cognitive and behavioral specialist. Whereas evidence of serotonergic deficit has prompted the use of selective serotonin reuptake inhibitors (SSRIs) to blunt impulsive and sexual behaviors in this cohort $[109,110]$, the centerpiece of treatment for diverse behavioral symptoms is working with available caregivers to develop nonpharmacologic strategies to modify behavior.

A model for behavioral intervention called DICE (describe, investigate, create, evaluate) is recommended, whereby a careful and structured investigation into root causes of problematic behavior is followed by the development of an action plan, with subsequent re-evaluation after implementation [111]. The developers of the DICE model also recommend searching for preventable/treatable causes of distress including untreated medical or psychiatric comorbidities, untreated pain, poor sleep hygiene, boredom and lack of sensory stimulation, a confrontational or overly nuanced caregiver communication style, an unpredictable daily routine, or an uncomfortable environment (e.g., chaotic, poorly lit, lack of recreational choices). Additionally, the development of a tailored action plan has been shown to reduce problematic behaviors in frontotemporal dementia [112].

\section{Agitation/Aggression}

Though agitation is infrequent and typically mild in 4Rtauopathies compared to other neurodegenerative diseases [113], when present, aggression poses a substantial challenge to caregivers and providers. The core of management is in providing behavioral strategies to the caregiver for redirection and environmental modification as discussed above. Specific strategies for management of agitation include implementation of any of a number of safe and low-cost activities: [1)] music therapy; [2)] pet therapy; [3)] aromatherapy, such as lemon balm or lavender oil; [4)] massage or touch therapy; [5)] initiation of regular physical activity such as walks or exercise training; [6)] scheduling of favorite hobbies; [7)] and person-centered communication skills training for caregivers [114].

Due to lack of clinical trials and low incidence of aggression in 4R-tauopathy, much of the rationale for pharmacologic management is necessarily extrapolated from other dementia cohorts. Similar to randomized clinical trial data on agitation in Alzheimer's disease [115], we see a modest positive effect with selective serotonin reuptake inhibitors such as citalopram. Antipsychotics should be avoided or only used for short durations in crisis situations, especially given the 
FDA black box warning of increased mortality in elderly patients with dementia and data from large multicenter clinical trials such as CATIE-AD, which showed that atypical antipsychotics were no more effective than SSRIs for behavioral control, and associated with a high rate of side effects such as extrapyramidal symptoms, sedation, and weight gain [116]. Other approaches commonly employed in other neurodegenerative disease including carbamazepine, valproic acid, and benzodiazepines have no role in aggression management in 4R-tauopathies because of cognitive and motor side effects. An ongoing trial is assessing the effect of low dose lithum on agitation and aggression in 60 patients with bvFTD (NCT02862210), though a trial in PSP-RS and CBS was stopped because the drug was poorly tolerated (NCT00703677).

\section{Anxiety/Depression}

Frequent screening for mood symptoms is recommended in all 4R-tauopathy syndromes, as patients are at high risk of suicide, and serotonergic deficit may be amenable to treatment with an SSRI [117]. Generally, SSRIs such as paroxetine should be avoided due to a larger anticholinergic effect [118], whereas citalopram, escitalopram, sertraline, and fluoxetine are commonly prescribed. If apathy is prominent, a serotonin-norepinephrine reuptake inhibitor (SNRI) or buproprion is a reasonable second-line agent. Tricyclic antidepressants were historically used for depressive symptoms, but cognitive, motor, and urologic side effects limit current utility $[119,120]$. Electroconvulsive therapy (ECT) was effective in a case report of refractory suicidal ideation in a patient with PSP-RS [121].

Cognitive behavioral therapy (CBT), either self-guided or provided by a licensed psychologist, may be an effective nonpharmacologic intervention for mood symptoms [122]. Mindfulness yoga reduced symptoms of depression and anxiety in a PD cohort, and may be similarly useful in 4Rtauopathy [123]. Numerous popular applications for guided meditation on mobile devices also can be safely recommended to patients, even if data on efficacy are lacking.

\section{Apathy}

Loss of motivation is often an early and unrecognized feature of many neurodegenerative diseases, including 4Rtauopathies, and may be mistaken for depressed mood. Apathy can be difficult to treat, but general strategies include selecting an activating antidepressant such as an SNRI, while avoiding SSRIs that may worsen apathy, e.g., citalopram and escitalopram [18]. A clinical trial is ongoing to assess the efficacy of intranasal oxytocin on treating apathy in patients with bvFTD (NCT03260920). Stimulants, such as methylphenidate, have clinical trial evidence for treatment of apathy in
Alzheimer's disease [124-126], but evidence for generalizability of these results to the 4R-tauopathy cohort is lacking. Regular exercise and scheduled activities are reasonable practical approaches without supportive research evidence.

\section{Other Symptoms}

\section{Insomnia/Fatigue}

Unlike in Alzheimer's disease, wake-promoting neurons are generally preserved in 4R-tauopathies [127], and therefore, sleep problems typically involve insomnia rather than hypersomnia [128]. In PSP-RS, severe insomnia is a characteristic feature, but unfortunately, evidence for effective therapeutics is limited, though an ongoing clinical trial is assessing the efficacy of zolpidem and suvorexant versus placebo (NCT04014387). Melatonin and trazodone are commonly prescribed, whereas benzodiazepines should be avoided. REM behavior disorder (RBD) can be present but is considerably less common than in synucleinopathies, and if early and prominent, RBD is an exclusion for PSP by MDS criteria. Sleep disordered breathing is a common comorbidity and screening for obstructive sleep apnea is recommended [129].

Advising on good sleep hygiene and cognitive behavioral therapy for sleep are 2 nonpharmacologic alternatives. Establishing a healthy sleep routine can also help with symptoms of fatigue, and the use of scheduled outings can help conserve limited energy, whereas breaks/naps can be used to recharge. Regular physical activity and exercise can be helpful for both sleep and energy levels.

\section{Urinary Control/Constipation}

Problems with urination in PSP-RS can include frequency, urgency, retention, and incontinence [130]. Typical pharmacologic agents such as anticholinergics (e.g., oxybutynin) should be avoided due to side effects of cognitive impairment and increased risk of dementia [131], and $\alpha 1$-adrenoceptor antagonists (e.g., tamsulosin) are associated with orthostatic hypotension that could increase falls [132]. Antispasmodics (e.g., tolterodine, trospium, solfenacin, darifenacin) are a reasonable alternative. Newer agents, such as mirabegron, have been proposed to lead to less cognitive impairment [133], though specific studies in 4R-tauopathies have not been conducted. Alternatives include the use of bladder training, pelvic floor exercises, and adult pads. Electrical stimulation therapies such as percutaneous tibial nerve stimulation (PTNS) and sacral neuromodulation therapy are occasionally employed. Intradetrusor injection of botulinum toxin can also be effective, and referral to a urologist is recommended for assistance in management.

Constipation is a common problem, often exacerbated by decreased fluid intake if urinary symptoms or dysphagia are 
present. Increased fluids, a high fiber diet, and regular physical activity and exercise are the foundation of treatment. If needed, polyethylene glycol, senna, lactulose, and bisacodyl suppositories are available over the counter.

\section{General Considerations}

\section{Education/Caregiver Support}

Many patients, caregivers, and providers are unfamiliar with 4R-tauopathies and their associated clinical syndromes, and education about the disease process can be a key therapeutic intervention, especially early in the disease course. Several resources are available for high-quality information about many syndromes caused by 4R-tau including CurePSP (www.psp.org), the Association for Frontotemporal Degeneration (www.theaftd.org), the PSP Association (pspassociation.org.uk), Rare Dementia Support (www. raredementiasupport.org), and the Alzheimer's Association (www.alz.org). Patients interested in observational research in the USA can be referred to the ALLFTD research consortium (www.allftd.org), whereas European and Canadian patients can be referred to the Genetic Frontotemporal Dementia Initiative (genfi.org.uk).

Given the multifactorial symptoms in 4R-tauopathies, caregiver burden is often high, so frequent screening for caregiver burnout and increasing caregiver support are key factors to successful management [134]. Several resources are available through organizations such as the Family Caregiver Alliance (www.caregiver.org), and options are available through social media platforms for those living remotely or who prefer not to attend in person. We recommend a multidisciplinary approach with a careful review of available resources and coping strategies at each visit.

\section{End-of-Life Planning}

Due to the progressive nature of neurodegenerative disease, discussion of goals of care should happen as early as possible, especially as judgment and reasoning may be impaired in later stages. Advance care planning should involve clarifying any limitations on treatments, including artificial feeding, resuscitation, and intensive care interventions, which can be recorded in documents such as the Physicians Orders for Life-Sustaining Treatment (POLST) form (www.polst.org). Financial and medical power of attorney forms should be completed, along with creation of a will or trusteeship, and an elder law attorney can be helpful if issues arise. Finally, early decisions on end of life, including preferred place of care, place of death (e.g., home, hospice, hospital), and funeral plans, can ensure a patient's wishes are respected through the end of their disease [135]. Autopsy and brain donation are options that can provide definitive diagnosis and assist in research efforts to find disease-modifying treatments.

\section{Future Disease-Modifying Treatment}

Currently, most proposed mechanisms for diseasemodifying treatment of 4R-tauopathies directly or indirectly target tau, though historically several early interventions were antioxidants purported to reduce mitochondrial stress and oxidative damage. The 2 overarching hypotheses being tested in tau-targeted clinical trials are that clinical improvement can be achieved by [1)] reducing a toxic gain of function caused by pathologic tau aggregates or [2)] restoring a loss of normal tau function [136]. Strategies that follow from the first hypothesis aim to reduce tau gene expression, prevent post-translational modifications that promote aggregation, or clear aggregates, usually via an immunologic mechanism, whereas strategies that target loss of function have focused on microtubule stabilization. Discussed below are all disease-modifying therapeutics that have reached the clinical trial phase in a 4R-tau-related clinical syndrome, grouped by mechanism (Table 3 ).

\section{Antioxidants}

As in many neurodegenerative diseases, oxidative stress and mitochondrial impairment have been observed in PSP, and antioxidants have been proposed as a therapeutic strategy $[148,149]$. Results have been published from 2 randomized placebo-controlled trials for coenzyme Q10 (CoQ10), and in an early phase 2 study, a modest positive effect was seen after 6 weeks of treatment with $5 \mathrm{mg} / \mathrm{kg}$ of CoQ10 in 21 patients on the PSP Rating Scale, but these results were not replicated in a larger trial conducted over 12 months in 61 patients, which did not achieve its target enrollment and was therefore underpowered to test the hypothesis that CoQ10 could slow disease progression $[137,150]$. Two other trials in PSP-RS have been registered on nutrient combinations with purported antioxidant activity: $\alpha$-lipolic acid with L-acetyl carnitine (Juvenon, NCT01537549) and pyruvate with creatinine and niacinamide (NCT00605930), but no efficacy was seen in the Juvenon trial with a high rate of side effects, and the second trial was stopped after the manufacturer of the supplement went bankrupt [151].

\section{Neuroprotective}

Riluzole is a benzothiazole currently used in the treatment of amyotrophic lateral sclerosis, with putative anti-excitotoxic activity through a range of pharmacologic effects, including 
Table 3 Disease-modifying clinical trials in 4R-tauopathy clinical syndromes

\begin{tabular}{|c|c|c|c|c|c|c|}
\hline Therapeutic & Mechanism & Cohort & Trial & Phase & Status & Result \\
\hline \multirow[t]{3}{*}{ CoQ10 } & \multirow[t]{3}{*}{ Antioxidant } & PSP-RS & NCT00328874 & 2 & Completed & $\begin{array}{l}\text { Safe, possibly } \\
\quad \text { effective [42] }\end{array}$ \\
\hline & & $\begin{array}{l}\text { PSP-RS or } \\
\text { CBS }\end{array}$ & NCT00532571 & $2 / 3$ & Completed & Not available \\
\hline & & PSP-RS & NCT00382824 & $2 / 3$ & Completed & $\begin{array}{l}\text { Safe, no effect seen } \\
\text { [137] }\end{array}$ \\
\hline $\begin{array}{l}\alpha \text {-Lipoic acid and L-acetyl } \\
\text { carnitine (Juvenon) }\end{array}$ & Antioxidant & PSP-RS & NCT01537549 & $1 / 2$ & Completed & Possibly harmful \\
\hline $\begin{array}{l}\text { Pyruvate, creatine, and } \\
\text { niacinamide }\end{array}$ & Antioxidant & PSP-RS & NCT00605930 & N/A & $\begin{array}{l}\text { Early } \\
\quad \text { terminated }\end{array}$ & Not available \\
\hline Riluzole & Neuroprotective & PSP-RS & $\begin{array}{l}\text { NCT00211224 } \\
\text { (NNIPPS) }\end{array}$ & 3 & Completed & $\begin{array}{l}\text { Safe, no effect seen } \\
\quad[138]\end{array}$ \\
\hline Rasagaline (Azilect) & MAO-B inhibitor & PSP-RS & NCT01187888 & 3 & Completed & $\begin{array}{l}\text { Safe, no effect seen } \\
\text { [139] }\end{array}$ \\
\hline Lithium & $\begin{array}{l}\text { GSK-3 } \beta \text { inhibitor } \\
\text { (nonselective) }\end{array}$ & $\begin{array}{l}\text { PSP-RS or } \\
\text { CBS }\end{array}$ & NCT00703677 & $1 / 2$ & Completed & Not tolerated \\
\hline Valproate (valproic acid) & $\begin{array}{l}\text { GSK-3 } \beta \text { inhibitor } \\
\text { (nonselective) }\end{array}$ & PSP-RS & NCT00385710 & 2 & Completed & Harmful [140] \\
\hline $\begin{array}{l}\text { Tideglusib (NP031112, Nypta, } \\
\text { Zentylor, NP12) }\end{array}$ & $\begin{array}{l}\text { GSK-3 } \beta \text { inhibitor } \\
\text { (selective) }\end{array}$ & $\begin{array}{l}\text { PSP-RS or } \\
\text { PSP-P }\end{array}$ & $\begin{array}{l}\text { NCT01049399 } \\
\text { (TAUROS) }\end{array}$ & 2 & Completed & $\begin{array}{l}\text { Safe, no effect seen } \\
\quad[141]\end{array}$ \\
\hline ASN120290 (ASN-561) & OGA inhibitor & PSP-RS & Not yet listed & 2 & $\begin{array}{l}\text { Not yet } \\
\text { recruiting }\end{array}$ & \\
\hline Young plasma & Cellular signaling & PSP-RS & NCT02460731 & 1 & Completed & $\begin{array}{l}\text { Safe, no effect seen } \\
{[142]}\end{array}$ \\
\hline Salsalate & Tau anti-acetylation & PSP-RS & NCT02422485 & 1 & Completed & $\begin{array}{l}\text { Safe, no effect seen } \\
{[142]}\end{array}$ \\
\hline TRx0237 (methylene blue) & $\begin{array}{l}\text { Tau aggregation inhibitor } \\
\text { (TAI) }\end{array}$ & bvFTD & NCT01626378 & 3 & Completed & $\begin{array}{l}\text { Safe, no effect seen } \\
\text { [143] }\end{array}$ \\
\hline AZP2006 & $\begin{array}{l}\text { Tau aggregation inhibitor } \\
\text { (TAI) }\end{array}$ & PSP-RS & NCT04008355 & 2 & $\begin{array}{l}\text { Not yet } \\
\text { recruiting }\end{array}$ & \\
\hline Davunetide (NAP, AL-108) & Microtubule stabilization & PSP-RS & NCT01110720 & $2 / 3$ & Completed & $\begin{array}{l}\text { Safe, no effect seen } \\
\text { [144] }\end{array}$ \\
\hline TPI 287 & Microtubule stabilization & $\begin{array}{l}\text { PSP-RS or } \\
\text { CBS }\end{array}$ & NCT02133846 & 1 & Completed & Harmful [145] \\
\hline AADvac-1 & $\begin{array}{l}\text { Active immunization } \\
\text { (vaccine) }\end{array}$ & nfvPPA & $\begin{array}{l}\text { NCT03174886 } \\
\text { (AIDA) }\end{array}$ & 1 & Ongoing & \\
\hline \multirow[t]{3}{*}{$\begin{array}{l}\text { BIIB092 (gosuranemab, } \\
\text { BMS-986168, IPN007) }\end{array}$} & \multirow{3}{*}{$\begin{array}{l}\text { Tau N-term monoclonal } \\
\text { antibodyN-terminal } \\
\text { (aa } 15-24)\end{array}$} & PSP-RS & NCT02460094 & 1 & Completed & $\begin{array}{r}\text { Safe, engaged } \\
\text { target [146] }\end{array}$ \\
\hline & & PSP-RS & $\begin{array}{l}\text { NCT03068468 } \\
\text { (PASSPORT) }\end{array}$ & 2 & Completed & No benefit \\
\hline & & $\begin{array}{l}\text { CBS, nfvPPA, } \\
\text { MAPT }\end{array}$ & $\begin{array}{r}\text { NCT03658135 } \\
\text { (TauBasket) }\end{array}$ & 1 & $\begin{array}{l}\text { Early } \\
\text { terminated }\end{array}$ & Not yet available \\
\hline \multirow{2}{*}{$\begin{array}{l}\text { ABBV-8E12 } \\
\text { (C2N 8E12, tilavonemab) }\end{array}$} & \multirow{2}{*}{$\begin{array}{l}\text { Tau N-term monoclonal anti- } \\
\text { body } \\
\text { N-terminal } \\
\text { (aa } 15-24)\end{array}$} & PSP-RS & NCT02494024 & 1 & Completed & Safe [147] \\
\hline & & PSP-RS & NCT02985879 & 2 & $\begin{array}{l}\text { Early } \\
\text { terminated }\end{array}$ & No benefit \\
\hline UCB 0107 & $\begin{array}{l}\text { Tau mid-domain monoclonal } \\
\text { antibody }\end{array}$ & PSP-RS & NCT04185415 & 2 & $\begin{array}{l}\text { Ongoing } \\
\text { (internation- } \\
\text { al) }\end{array}$ & - \\
\hline Tolfenamic acid & $\begin{array}{l}\text { Degrades tau transcription } \\
\text { factor }\end{array}$ & PSP-RS & NCT04253132 & 2 & Ongoing & - \\
\hline
\end{tabular}

inhibition of glutamate-mediated apoptosis [152]. As part of a larger study in "Parkinson's-Plus" diseases, riluzole was tested in 362 patients with PSP-RS, but no effect was seen on survival after 36 months [138].

\section{MAO-B Inhibition}

The type B monoamine oxidase (MAO) inhibitor rasagaline advanced into clinical trials for PSP-RS based on history of 
safe use in Parkinson's combined with evidence of neuroprotection in cellular and animal models, possibly through an increase of endogenous neurotrophic factors [153]. Unfortunately, in a 12-month randomized placebo-controlled trial of rasagaline ( $1 \mathrm{mg}$ daily) in 44 patients with PSP-RS, no effect was seen on progression as measured by the primary outcome, the PSP Rating Scale, and, although underpowered, no trend towards efficacy was observed [139].

\section{GSK-3 $\beta$ Inhibition}

Glycogen synthase kinase 3 beta (GSK- $3 \beta$ ) is a serine/ threonine kinase that phosphorylates tau and has been shown to promote the formation of the neurofibrillary tangles seen in Alzheimer's disease [154]. In addition to this role in AD pathology, GSK-3 $\beta$ is also involved in a wide range of cellular processes, including differentiation, growth, motility, and apoptosis [155]. Lithium is more commonly known as a mood stabilizer, but a GSK-3 $\beta$-dependent reduction in tau hyperphosphorylation was found in mouse models [156], and a clinical trial was started to evaluate lithium in PSP-RS, but lithium was very poorly tolerated and the trial was stopped early due to a high discontinuation rate (NCT00703677). Valproate is another mood stabilizer with putative action on through GSK-3 $\beta$ inhibition [157], but a randomized controlled trial in 28 patients with PSP-RS showed no difference on disease progression, with possible worsening on measures of gait, again suggesting poor tolerability [140]. It should be noted that both lithium and valproate are nonselective for GSK $3 \beta$, and thus, observed toxicity may be due to off-target effects.

Tideglusib is a small molecule designed as a selective GSK-3 $\beta$ inhibitor [158], but in TAUROS, a phase 2 randomized controlled trial in 146 patients with PSP-RS, 52 weeks of treatment with tideglusib was well tolerated but lacked efficacy [141]. Some authors have suggested that because no measures of target engagement were incorporated into the above trials, it was not possible to determine whether sufficient GSK-3 $\beta$ inhibition occurred to have an effect [159]. However, development for tideglusib has been discontinued, and no other GSK-3 $\beta$ inhibitors are in clinical development at present, though approaches using other kinase inhibitors are being tested in Alzheimer's disease and could be considered in 4R-tauopathies.

\section{OGA Inhibition}

A glycosylation process called O-GlcNAcylation involves attachment of an $\mathrm{N}$-acetylglucosamine group (GlcNAc) to serine/threonine sites, and these O-GlcNAc residues are removed by the enzyme O-GlcNAcase (OGA). Decreased OGlcNAcylation levels are associated with pathologic tau hyperphosphorylation, and, in the human AD brain, O-
GlcNAcylation levels are decreased 50\%, which provides rationale for the development of an OGA inhibitor in tauopathies [160, 161]. The first novel OGA inhibitor was MK-8719, developed by Merck, which was well tolerated in healthy controls and showed good target engagement as measured by the use of a novel OGA radiotracer [18F]MK-8553 [162]. Despite Merck announcing a trial for PSP patients, MK-8719 never advanced into clinical trials in this cohort, and development has been discontinued [163].

ASN120290 is another novel OGA inhibitor, and preclinical data in 4R-tauopathy transgenic mice show an increase in O-GlcNAcylated tau and a decrease in phosphorylated tau [164]. In phase 1 studies, ASN120290 was safe and well tolerated [165], and the developer, Asceneuron, has announced the intention to move it into phase 2 clinical trials for the PSPRS.

\section{Cellular Signaling}

Young plasma (i.e., fresh frozen plasma derived from healthy donors under the age of 30) advanced into clinical trials for Alzheimer's disease and PSP-RS without a definitive mechanism, but with evidence of functional improvement in cognition in mouse models of AD and aging [166-168]. In a pilot open-label trial in 5 patients with PSP-RS, young plasma was found to be safe, but no evidence for efficacy was seen on a range of outcomes [142].

\section{Inhibition of Tau Acetylation}

Clearance of tau is dependent on proteasomes, and acetylation of tau prevents ubiquitination and routing to the proteasome system, promoting tau aggregation [169]. In 4R-tau transgenic mice, treatment with salsalate, a nonsteroidal antiinflammatory agent with inhibitory action on the acetyltransferase p300, decreased tau aggregation and rescued memory deficits, providing support for clinical trials [170]. However, in a small open-label trial in 9 patients with PSP-RS, salsalate (2250 mg daily) was safe and well tolerated, but no effect was seen on a range of outcomes including the PSP Rating Scale after treatment for 6 months [142].

\section{Tau Aggregation Inhibitors}

Methylene blue is a phenothiazine that was found to disrupt high-affinity tau-tau bonds, and in transgenic mice, it decreased tau aggregates and rescued memory if given prior to symptom onset [171-173]. A reduced formulation of methylene blue called TRx0237 was tested in a phase 3 randomized control trial for 220 patients with bvFTD, and at $200 \mathrm{mg}$ daily was found to be safe, but no effect was seen on any primary or secondary endpoint compared to placebo [143], and a parallel randomized controlled trial in 891 patients with mild to 
moderate Alzheimer's disease also failed to show a benefit [174]. However, methylene blue is a biologic dye that turns urine and feces blue, and $8 \mathrm{mg}$ was included in placebo to preserve blinding, and under the hypothesis that this low dose may be effective, which would confound prior analyses, a new randomized controlled trial is enrolling to test low-dose TRx0237 in 450 patients with mild AD (NCT03446001).

AZP2006 is another agent with a putative mechanism of decreasing tau aggregation via blocking of phosphorylation, and although details on mechanism have not been published, in a phase 1 trial in France, AZP2006 was reportedly well tolerated [175]. A phase 2 clinical trial in PSP-RS has been announced, with a plan to treat with 2 doses of AZP2006 in 36 PSP-RS patients for 29 weeks (NCT04008355).

\section{Microtubule Stabilizers}

An alternative hypothesis for dysfunction in tauopathies is that tau loss of function, specifically loss of microtubule stabilization, may be driving pathology, and thus far, 2 agents have been tested in clinical trials in 4R-tauopathy that are proposed to act through microtubule stabilization. The first is davunetide, a neuropeptide growth factor with diverse neuroprotective activity in cell and animal models [176-178]. Unfortunately, in one of the first large multicenter randomized control trials in PSP-RS, davunetide did not meet its primary endpoint in 360 patients treated for 52 weeks [144]. The second agent, TPI 287, a taxane derivative, was evaluated in a basket design for AD, PSP, and CBS patients, but a doserelated worsening of falls and cognitive outcomes was seen in the 4R-tauopathy arms, and this agent is no longer in clinical development [145].

\section{Immunotherapies}

Approaches that harness the immune system to clear tau aggregation have generated significant interest in the 4Rtauopathy clinical trial world at present, and both active and passive immune strategies are being investigated. Active immunization, i.e. vaccination, was the first area of investigation, but early studies looking at full-length tau inoculation in mouse models provoked severe inflammation and further tau aggregation [179], which incidentally provided the first evidence of tau "seeding" hypothesis as a mechanism of pathogenic spread, later supported in other experimental models [180]. More recent therapeutic active vaccination strategies, such as AADvac1, use fragments of tau that do not trigger tau aggregation but do provoke a B-cell-mediated immune response, and in transgenic rat models, AADvac1 reduced tau aggregation and improved motor function [181]. In addition to several ongoing trials in $\mathrm{AD}$ which have demonstrated clear immunogenicity $[182,183]$, AADvac1 is being tested in a phase 1 study in 30 patients with nfvPPA, and the trial is designed to assess safety and immunogenicity in this population (NCT03174886), with results expected in late 2020.

Passive immune clearance occurs via infusion of monoclonal antibodies designed to target particular epitopes on the tau protein, though the appropriate epitope to target is controversial and remains a matter of ongoing investigation. BIIB092 (gosuranemab) is a monoclonal IgG4 antibody against the $\mathrm{N}$ terminal region of tau (amino acids 15-23), and in cell culture and animal models, it reduced both full-length tau and extracellular tau fragments [184]. A 3-month phase 1 study in 58 PSP-RS patients showed BIIB092 to be safe and demonstrated target engagement by reduction in N-terminal tau [146]. However, an interim analysis in a subsequent phase 2 study in PSP-RS patients (PASSPORT, NCT03068468) found no trend towards efficacy on primary endpoints, and PASSPORT was terminated early for futility. A parallel study with a basket design (TauBasket) was providing expanded access in other 4R-tauopathies including CBS, nfvPPA, and MAPT, but this study was terminated due to the futility analysis results from PASSPORT.

ABBV 8E12 (tilavonemab) is a second monoclonal antibody that targets the $\mathrm{N}$-terminal (amino acids 25-30) [185-187], and a phase 1 study in 32 PSP patients showed ABBV 8E12 was safe [147], but an interim analysis in a subsequent phase 2 study in 378 PSP-RS patients (NCT02985879) also showed futility, and this trial was terminated early.

An alternative epitope is the midregion of tau, which is closer to the microtubule binding repeat regions, and in a seeding model of tau in transgenic mice, only antibodies that targeted the mid-domain suppressed tau aggregation, whereas $\mathrm{N}$-terminal antibodies did not [188]. A monoclonal antibody to the mid-domain (amino acids 235-246), UCB0107, recently completed Phase 1 studies in healthy controls, and an international Phase 2 trial in 16 patients with PSP-RS has been announced and is currently recruiting (NCT04185415), while a US trial is in development but no information is publicly available.

\section{Gene Expression}

Given the diverse roles of tau in the human brain, regulation of tau at the gene level has been approached cautiously, but reassuringly, tau knockout mice have a very mild phenotype [189]. Currently, the only clinical trial putatively affecting tau expression in 4R-tauopathy is a recently announced phase 2 randomized controlled trial of tolfenamic acid in PSP-RS (NCT04253132), which promotes the degradation of specificity protein $1(\mathrm{Sp} 1)$, a transcription factor that upregulates tau [190]. However, given the recent successes in employing an antisense oligonucleotide approach in spinal muscular atrophy and Huntington's disease [191, 192], and data showing that ASO-mediated reduction of tau translation by $50 \%$ reduced 
tau aggregation and prevented neuronal loss in transgenic mouse models [193], there is substantial enthusiasm for testing tau-targeted ASOs in 4R-tauopathies. MAPTRx is a nonselective tau-targeted ASO developed by Ionis that is being tested in a randomized controlled trial in 46 patients with mild AD (NCT03186989), with results expected in late 2020.

\section{Conclusion}

Twenty disease-modifying therapeutics have been entered into clinical trials for the treatment of a 4R-tauopathy-related syndrome at the time of this review, and increasingly, therapeutics targeting the neurofibrillary tau tangles in Alzheimer's disease are being cross-purposed into this cohort. However, although patients with 4R-tauopathies are increasingly being included in clinical trials, no approach to date has specifically targeted 4R-tau, which represents both an unmet medical need and an unexplored avenue for research. Over the last several decades, trial design in 4R-tauopathies has advanced considerably, especially for PSP-RS, in which the underlying neuropathology is highly predictable, and the rate of decline is typically faster than in other neurodegenerative disease, allowing a reliably identifiable and homogenous clinical cohort, with a shorter trial design needed than in Alzheimer's disease. Additionally, novel "basket" designs borrowed from the oncological trial literature are allowing trials in 4Rtauopathy clinical syndromes that are typically without available experimental treatments (NCT03658135, NCT02133846).

Selection of clinically relevant outcomes has been facilitated by several multicenter clinical and observational trials showing striking consistency in several clinical endpoints [194], including the PSP Rating Scale [195], the Schwab and England Activity of Daily Living scale (SEADL) [196], the Repeatable Battery for the Assessment of Neuropsychological Status (RBANS) [197], and neurofilament light chain (NfL) concentrations in the blood and cerebrospinal fluid [198]. And although the current tau positron emission tomography (PET) radiotracers do not appear sensitive for 4R-tau deposits [199], several more recent and promising efforts may yet yield a 4R-tau imaging biomarker that could replace the current use of volumetric MRI measures of midbrain atrophy to detect PSP-RS.

Taken together, the rapid pace of drug development and recent innovations in trial design will hopefully herald a new age in the treatment of 4R-tauopathies, and a clinically meaningful disease-modifying therapeutic will become available in the coming years. In the interim, numerous pharmacologic and nonpharmacologic approaches can ameliorate symptoms and maintain function for patients suffering from 4Rtauopathies, and a multidisciplinary approach to their care can lead to a significant improvement in quality of life, as these patients urgently await a needed treatment.

Acknowledgments This work was funded by the National Institute on Aging (NIA) through 5T32AG023481 (Lawren Vande Vrede), K23AG059888 (Julio C. Rojas), 5R01AG038791-09 (Adam L. Boxer), and 1U19AG063911-01 (Adam L. Boxer), the Tau Consortium (Lawren Vande Vrede, Adam L. Boxer), and the National Institute for Neurological Disorders and Stroke (NINDS) through R01NS050915 (Ariane E. Welch). Adam L. Boxer has also received research support from Bluefield Project to Cure Frontotemporal Dementia, Corticobasal Degeneration Solutions, the Alzheimer's Drug Discovery Foundation, and the Alzheimer's Association. He has served as a consultant for Aeton, Abbvie, Alector, Amgen, Arkuda, Arvinas, Asceneuron, Ionis, Lundbeck, Novartis, Passage BIO, Samumed, Third Rock, Toyama, and UCB, and received research support from Avid, Biogen, BMS, C2N, Cortice, Eli Lilly, Forum, Genentech, Janssen, Novartis, Pfizer, Roche, and TauRx. The authors have no further conflicts of interest to report.

Required Author Forms Disclosure forms provided by the authors are available with the online version of this article.

\section{References}

1. Lee, V.M., M. Goedert, and J.Q. Trojanowski, Neurodegenerative tauopathies. Annu Rev Neurosci, 2001. 24: p. 1121-1159.

2. Goedert, M., M.G. Spillantini, R. Jakes, D. Rutherford, and R.A. Crowther, Multiple isoforms of human microtubule-associated protein tau: sequences and localization in neurofibrillary tangles of Alzheimer's disease. Neuron, 1989. 3(4): p. 519-526.

3. Goedert, M. and R. Jakes, Expression of separate isoforms of human tau protein: correlation with the tau pattern in brain and effects on tubulin polymerization. EMBO J, 1990. 9(13): p. 42254230 .

4. Spillantini, M.G., T.D. Bird, and B. Ghetti, Frontotemporal dementia and Parkinsonism linked to chromosome 17: a new group of tauopathies. Brain Pathol, 1998. 8(2): p. 387-402.

5. Kovacs, G.G., Invited review: Neuropathology of tauopathies: principles and practice. Neuropathol Appl Neurobiol, 2015. 41(1): p. 3-23.

6. Dickson, D.W., Z. Ahmed, A.A. Algom, Y. Tsuboi, and K.A. Josephs, Neuropathology of variants of progressive supranuclear palsy. Curr Opin Neurol, 2010. 23(4): p. 394-400.

7. Dickson, D.W., C. Bergeron, S.S. Chin, et al., Office of Rare Diseases neuropathologic criteria for corticobasal degeneration. J Neuropathol Exp Neurol, 2002. 61(11): p. 935-946.

8. Armstrong, M.J., I. Litvan, A.E. Lang, et al., Criteria for the diagnosis of corticobasal degeneration. Neurology, 2013. 80(5): p. 496-503.

9. Hoglinger, G.U., G. Respondek, M. Stamelou, et al., Clinical diagnosis of progressive supranuclear palsy: The movement disorder society criteria. Mov Disord, 2017. 32(6): p. 853-864.

10. Coyle-Gilchrist, I.T., K.M. Dick, K. Patterson, et al., Prevalence, characteristics, and survival of frontotemporal lobar degeneration syndromes. Neurology, 2016. 86(18): p. 1736-1743.

11. Gorno-Tempini, M.L., A.E. Hillis, S. Weintraub, et al., Classification of primary progressive aphasia and its variants. Neurology, 2011. 76(11): p. 1006-1014.

12. Lee, S.E., G.D. Rabinovici, M.C. Mayo, et al., Clinicopathological correlations in corticobasal degeneration. Ann Neurol, 2011. 70(2): p. 327-340. 
13. Respondek, G., M.J. Grimm, I. Piot, et al., Validation of the movement disorder society criteria for the diagnosis of 4-repeat tauopathies. Mov Disord, 2020. 35(1): p. 171-176.

14. Saranza, G.M., J.L. Whitwell, G.G. Kovacs, and A.E. Lang, Corticobasal degeneration. Int Rev Neurobiol, 2019. 149: p. 87136.

15. Hoglinger, G.U., Is it useful to classify progressive supranuclear palsy and corticobasal degeneration as different disorders? No Mov Disord Clin Pract, 2018. 5(2): p. 141-144.

16. Rosler, T.W., A. Tayaranian Marvian, M. Brendel, et al., Fourrepeat tauopathies. Prog Neurobiol, 2019. 180: p. 101644.

17. Greene, P., Progressive supranuclear palsy, corticobasal degeneration, and multiple system atrophy. Continuum (Minneap Minn), 2019. 25(4): p. 919-935.

18. McFarland, N.R., Diagnostic approach to atypical Parkinsonian syndromes. Continuum (Minneap Minn), 2016. 22(4 Movement Disorders): p. 1117-1142.

19. Arendt, T., J.T. Stieler, and M. Holzer, Tau and tauopathies. Brain Res Bull, 2016. 126(Pt 3): p. 238-292.

20. Oyanagi, K., K. Tsuchiya, M. Yamazaki, and K. Ikeda, Substantia nigra in progressive supranuclear palsy, corticobasal degeneration, and parkinsonism-dementia complex of Guam: specific pathological features. J Neuropathol Exp Neurol, 2001. 60(4): p. 393-402.

21. Litvan, I., D.A. Grimes, A.E. Lang, et al., Clinical features differentiating patients with postmortem confirmed progressive supranuclear palsy and corticobasal degeneration. J Neurol, 1999. 246 Suppl 2: p. II1-15.

22. Kompoliti, K., C.G. Goetz, I. Litvan, K. Jellinger, and M. Verny, Pharmacological therapy in progressive supranuclear palsy. Arch Neurol, 1998. 55(8): p. 1099-1102.

23. Litvan I., Chase T.N., Traditional and experimental therapeutic approaches. Progressive supranuclear palsy: clinical and research approaches., ed. I. Litvan. 1992, New York: Oxford University Press.

24. Colosimo, C., M. Merello, and F.E. Pontieri, Amantadine in parkinsonian patients unresponsive to levodopa: a pilot study. J Neurol, 1996. 243(5): p. 422-425.

25. Rittman, T., I.T. Coyle-Gilchrist, and J.B. Rowe, Managing cognition in progressive supranuclear palsy. Neurodegener Dis Manag, 2016. 6(6): p. 499-508.

26. Giagkou, N. and M. Stamelou, Therapeutic management of the overlapping syndromes of atypical parkinsonism. CNS Drugs, 2018. 32(9): p. 827-837.

27. O'Sullivan, S.S., A.H. Evans, and A.J. Lees, Dopamine dysregulation syndrome: an overview of its epidemiology, mechanisms and management. CNS Drugs, 2009. 23(2): p. 157-70.

28. Weiner, W.J., A. Minagar, and L.M. Shulman, Pramipexole in progressive supranuclear palsy. Neurology, 1999. 52(4): p. 873-4.

29. Kompoliti, K., C.G. Goetz, B.F. Boeve, et al., Clinical presentation and pharmacological therapy in corticobasal degeneration. Arch Neurol, 1998. 55(7): p. 957-61.

30. Clerici, I., D. Ferrazzoli, R. Maestri, et al., Rehabilitation in progressive supranuclear palsy: Effectiveness of two multidisciplinary treatments. PLoS One, 2017. 12(2): p. e0170927.

31. Rajput, A. and A.H. Rajput, Progressive supranuclear palsy: clinical features, pathophysiology and management. Drugs Aging, 2001. 18(12): p. 913-925.

32. Umemoto, G. and H. Furuya, Management of dysphagia in patients with Parkinson's disease and related disorders. Intern Med, 2020. 59(1): p. 7-14.

33. Lange-Alberts, M.E. and S. Shott, Nutritional intake. Use of touch and verbal cuing. J Gerontol Nurs, 1994. 20(2): p. 36-40.

34. Van Ort, S. and L.R. Phillips, Nursing intervention to promote functional feeding. J Gerontol Nurs, 1995. 21(10): p. 6-14.

35. Walshe, M., Oropharyngeal dysphagia in neurodegenerative disease. J Gastroenterol Hepatol Res, 2014. 3(10): p. 1265-1271.
36. Mancopes, R., S. Smaoui, and C.M. Steele, Effects of expiratory muscle strength training on videofluoroscopic measures of swallowing: a systematic review. Am J Speech Lang Pathol, 2020. 29(1): p. 335-356.

37. Miles, A., M. Jardine, F. Johnston, M. de Lisle, P. Friary, and J. Allen, Effect of Lee Silverman Voice Treatment (LSVT LOUD(R)) on swallowing and cough in Parkinson's disease: a pilot study. J Neurol Sci, 2017. 383: p. 180-187.

38. Park, J.S., D.H. Oh, N.K. Hwang, and J.H. Lee, Effects of neuromuscular electrical stimulation in patients with Parkinson's disease and dysphagia: a randomized, single-blind, placebocontrolled trial. NeuroRehabilitation, 2018. 42(4): p. 457-463.

39. Plowman, E.K., L. Tabor-Gray, K.M. Rosado, et al., Impact of expiratory strength training in amyotrophic lateral sclerosis: results of a randomized, sham-controlled trial. Muscle Nerve, 2019. 59(1): p. 40-46.

40. Tang, Y., X. Lin, X.J. Lin, et al., Therapeutic efficacy of neuromuscular electrical stimulation and electromyographic biofeedback on Alzheimer's disease patients with dysphagia. Medicine (Baltimore), 2017. 96(36): p. e8008.

41. Palecek, E.J., J.M. Teno, D.J. Casarett, L.C. Hanson, R.L. Rhodes, and S.L. Mitchell, Comfort feeding only: a proposal to bring clarity to decision-making regarding difficulty with eating for persons with advanced dementia. J Am Geriatr Soc, 2010. 58(3): p. 580584 .

42. Stamelou, M., A. Alonso-Canovas, and K.P. Bhatia, Dystonia in corticobasal degeneration: a review of the literature on 404 pathologically proven cases. Mov Disord, 2012. 27(6): p. 696-702.

43. Muller, J., G.K. Wenning, J. Wissel, K. Seppi, and W. Poewe, Botulinum toxin treatment in atypical parkinsonian disorders associated with disabling focal dystonia. J Neurol, 2002. 249(3): p. 300-304.

44. Unti, E., S. Mazzucchi, R. Calabrese, et al., Botulinum toxin for the treatment of dystonia and pain in corticobasal syndrome. Brain Behav, 2019. 9(6): p. e01182.

45. Armstrong, M.J., Diagnosis and treatment of corticobasal degeneration. Curr Treat Options Neurol, 2014. 16(3): p. 282.

46. Gibb, W.R., P.J. Luthert, and C.D. Marsden, Corticobasal degeneration. Brain, 1989. 112 ( Pt 5): p. 1171-1192.

47. Jinnah, H.A. and S.A. Factor, Diagnosis and treatment of dystonia. Neurol Clin, 2015. 33(1): p. 77-100.

48. Delnooz, C.C., M.W. Horstink, M.A. Tijssen, and B.P. van de Warrenburg, Paramedical treatment in primary dystonia: a systematic review. Mov Disord, 2009. 24(15): p. 2187-2198.

49. Zwergal, A., C. la Fougere, S. Lorenzl, et al., Functional disturbance of the locomotor network in progressive supranuclear palsy. Neurology, 2013. 80(7): p. 634-641.

50. Bluett, B., I. Litvan, S. Cheng, et al., Understanding falls in progressive supranuclear palsy. Parkinsonism Relat Disord, 2017. 35: p. $75-81$.

51. Williams, D.R., H.C. Watt, and A.J. Lees, Predictors of falls and fractures in bradykinetic rigid syndromes: a retrospective study. $\mathrm{J}$ Neurol Neurosurg Psychiatry, 2006. 77(4): p. 468-473.

52. Suteerawattananon, M., B. MacNeill, and E.J. Protas, Supported treadmill training for gait and balance in a patient with progressive supranuclear palsy. Phys Ther, 2002. 82(5): p. 485-495.

53. Sosner, J., G.C. Wall, and J. Sznajder, Progressive supranuclear palsy: clinical presentation and rehabilitation of two patients. Arch Phys Med Rehabil, 1993. 74(5): p. 537-539.

54. Monticone, M., E. Ambrosini, A. Laurini, B. Rocca, and C. Foti, In-patient multidisciplinary rehabilitation for Parkinson's disease: a randomized controlled trial. Mov Disord, 2015. 30(8): p. 10501058.

55. Li, F., P. Harmer, K. Fitzgerald, et al., Tai chi and postural stability in patients with Parkinson's disease. N Engl J Med, 2012. 366(6): p. $511-519$. 
56. Dos Santos Delabary, M., I.G. Komeroski, E.P. Monteiro, R.R. Costa, and A.N. Haas, Effects of dance practice on functional mobility, motor symptoms and quality of life in people with Parkinson's disease: a systematic review with meta-analysis. Aging Clin Exp Res, 2018. 30(7): p. 727-735.

57. Teixeira-Machado, L., F.M. Araujo, F.A. Cunha, M. Menezes, T. Menezes, and J. Melo DeSantana, Feldenkrais method-based exercise improves quality of life in individuals with Parkinson's disease: a controlled, randomized clinical trial. Altern Ther Health Med, 2015. 21(1): p. 8-14.

58. Combs, S.A., M.D. Diehl, W.H. Staples, et al., Boxing training for patients with Parkinson disease: a case series. Phys Ther, 2011. 91(1): p. 132-142.

59. Sandyk, R., Transcranial AC pulsed applications of weak electromagnetic fields reduces freezing and falling in progressive supranuclear palsy: a case report. Int J Neurosci, 1998. 94(1-2): p. $41-54$

60. Rajput, A.H., B. Rozdilsky, and L. Ang, Occurrence of resting tremor in Parkinson's disease. Neurology, 1991. 41(8): p. 1298-9.

61. Litvan, I., Y. Agid, C. Goetz, et al., Accuracy of the clinical diagnosis of corticobasal degeneration: a clinicopathologic study. Neurology, 1997. 48(1): p. 119-125.

62. Notturno, F., F. Zappasodi, V. Maruotti, L. Marzetti, M. Caulo, and A. Uncini, Cortical origin of myoclonus in early stages of corticobasal degeneration. Mov Disord, 2011. 26(8): p. 15671569.

63. Marsili, L., A. Suppa, A. Berardelli, and C. Colosimo, Therapeutic interventions in parkinsonism: corticobasal degeneration. Parkinsonism Relat Disord, 2016. 22 Suppl 1: p. S96-100.

64. Cho, J.W. and J.H. Lee, Suppression of myoclonus in corticobasal degeneration by levetiracetam. J Mov Disord, 2014. 7(1): p. 2830 .

65. Kluin, K., S. Gilman, N. Foster, et al., Neuropathological correlates of dysarthria in progressive supranuclear palsy. Arch Neurol, 2001. 58(2): p. 265-269.

66. Kluin, K.J., N.L. Foster, S. Berent, and S. Gilman, Perceptual analysis of speech disorders in progressive supranuclear palsy. Neurology, 1993. 43(3 Pt 1): p. 563-566.

67. Rusz, J., C. Bonnet, J. Klempir, et al., Speech disorders reflect differing pathophysiology in Parkinson's disease, progressive supranuclear palsy and multiple system atrophy. J Neurol, 2015. 262(4): p. 992-1001.

68. Skodda, S., W. Visser, and U. Schlegel, Acoustical analysis of speech in progressive supranuclear palsy. J Voice, 2011. 25(6): p. 725-731.

69. Frattali, C., J.R. Duffy, I. Litvan, A.D. Patsalides, and J. Grafman, Yes/no reversals as neurobehavioral sequela: a disorder of language, praxis, or inhibitory control? Eur J Neurol, 2003. 10(1): p. 103-106.

70. Peterson, K.A., K. Patterson, and J.B. Rowe, Language impairment in progressive supranuclear palsy and corticobasal syndrome. J Neurol, 2019.

71. Volkmer, A., E. Rogalski, M. Henry, et al., Speech and language therapy approaches to managing primary progressive aphasia. Pract Neurol, 2020. 20(2): p. 154-161.

72. Bailey, R.L., H.P. Parette, Jr., J.B. Stoner, M.E. Angell, and K. Carroll, Family members' perceptions of augmentative and alternative communication device use. Lang Speech Hear Serv Sch, 2006. 37(1): p. 50-60.

73. Smiljanic, R. and A.R. Bradlow, Speaking and hearing clearly: talker and listener factors in speaking style changes. Lang Linguist Compass, 2009. 3(1): p. 236-264.

74. Van Nuffelen, G., M. De Bodt, J. Vanderwegen, P. Van de Heyning, and F. Wuyts, Effect of rate control on speech production and intelligibility in dysarthria. Folia Phoniatr Logop, 2010. 62(3): p. 110-9.
75. Yorkston, K.M., M. Hakel, D. Beukelman, and S. Fager, Evidence for effectiveness of treatment of loudness, rate, or prosody in dysarthria: a systematic review. J Med Speech Lang Pathol, 2007. 15: p. xi-xxxvi.

76. McDonnell, M.N., B. Rischbieth, T.T. Schammer, C. Seaforth, A.J. Shaw, and A.C. Phillips, Lee Silverman Voice Treatment (LSVT)-BIG to improve motor function in people with Parkinson's disease: a systematic review and meta-analysis. Clin Rehabil, 2018. 32(5): p. 607-618.

77. Ahmed, A. and Z. Simmons, Pseudobulbar affect: prevalence and management. Ther Clin Risk Manag, 2013. 9: p. 483-9.

78. Hammond, F.M., D.N. Alexander, A.J. Cutler, et al., PRISM II: an open-label study to assess effectiveness of dextromethorphan/ quinidine for pseudobulbar affect in patients with dementia, stroke or traumatic brain injury. BMC Neurol, 2016. 16: p. 89.

79. Smith, R., E. Pioro, K. Myers, et al., Enhanced bulbar function in amyotrophic lateral sclerosis: The Nuedexta Treatment Trial. Neurotherapeutics, 2017. 14(3): p. 762-772.

80. Pioro, E.P., B.R. Brooks, J. Cummings, et al., Dextromethorphan plus ultra low-dose quinidine reduces pseudobulbar affect. Ann Neurol, 2010. 68(5): p. 693-702.

81. Litvan, I., R. Blesa, K. Clark, et al., Pharmacological evaluation of the cholinergic system in progressive supranuclear palsy. Ann Neurol, 1994. 36(1): p. 55-61.

82. Costa, J., C. Espirito-Santo, A. Borges, et al., Botulinum toxin type A therapy for blepharospasm. Cochrane Database Syst Rev, 2005(1): p. CD004900.

83. Krack, P. and M.H. Marion, "Apraxia of lid opening," a focal eyelid dystonia: clinical study of 32 patients. Mov Disord, 1994. 9(6): p. 610-615.

84. Daniele, A., E. Moro, and A.R. Bentivoglio, Zolpidem in progressive supranuclear palsy. N Engl J Med, 1999. 341(7): p. 543-544.

85. Cotter, C., T. Armytage, and D. Crimmins, The use of zolpidem in the treatment of progressive supranuclear palsy. J Clin Neurosci, 2010. 17(3): p. 385-386.

86. Rabinovici, G.D., M.L. Stephens, and K.L. Possin, Executive dysfunction, Continuum (Minneap Minn) 2015. 21(3 Behavioral Neurology and Neuropsychiatry): p. 646-659.

87. Deckers, K., M.P. van Boxtel, O.J. Schiepers, et al., Target risk factors for dementia prevention: a systematic review and Delphi consensus study on the evidence from observational studies. Int $\mathrm{J}$ Geriatr Psychiatry, 2015. 30(3): p. 234-246.

88. Rogalski, E.J. and B. Khayum, A life participation approach to primary progressive aphasia intervention. Semin Speech Lang, 2018. 39(3): p. 284-296.

89. Henry, M.L., K. Rising, A.T. DeMarco, B.L. Miller, M.L. GornoTempini, and P.M. Beeson, Examining the value of lexical retrieval treatment in primary progressive aphasia: two positive cases. Brain Lang, 2013. 127(2): p. 145-156.

90. Tippett, D.C., A.E. Hillis, and K. Tsapkini, Treatment of primary progressive aphasia. Curr Treat Options Neurol, 2015. 17(8): p. 362.

91. Brenowitz, W.D., A.R. Kaup, F.R. Lin, and K. Yaffe, Multiple sensory impairment is associated with increased risk of dementia among black and white older adults. J Gerontol A Biol Sci Med Sci, 2019. 74(6): p. 890-896.

92. Gurgel, R.K., P.D. Ward, S. Schwartz, M.C. Norton, N.L. Foster, and J.T. Tschanz, Relationship of hearing loss and dementia: a prospective, population-based study. Otol Neurotol, 2014. 35(5): p. $775-781$

93. Henry, M.L., H.I. Hubbard, S.M. Grasso, et al., Retraining speech production and fluency in non-fluent/agrammatic primary progressive aphasia. Brain, 2018. 141(6): p. 1799-1814.

94. Henry, M.L., M.V. Meese, S. Truong, M.C. Babiak, B.L. Miller, and M.L. Gorno-Tempini, Treatment for apraxia of speech in 
nonfluent variant primary progressive aphasia. Behav Neurol, 2013. 26(1-2): p. 77-88.

95. Dial, H.R., H.A. Hinshelwood, S.M. Grasso, H.I. Hubbard, M.L. Gorno-Tempini, and M.L. Henry, Investigating the utility of teletherapy in individuals with primary progressive aphasia. Clin Interv Aging, 2019. 14: p. 453-471.

96. Madden, D.L., M.V. Sale, J. O'Sullivan, and G.A. Robinson, Improved language production with transcranial direct current stimulation in progressive supranuclear palsy. Neuropsychologia, 2019. 127: p. 148-157.

97. Cotelli, M., R. Manenti, M. Petesi, et al., Treatment of primary progressive aphasias by transcranial direct current stimulation combined with language training. J Alzheimers Dis, 2014. 39(4): p. $799-808$.

98. Fried-Oken, M., A. Mooney, and B. Peters, Supporting communication for patients with neurodegenerative disease. NeuroRehabilitation, 2015. 37(1): p. 69-87.

99. Kagan, A., Supported conversation for adults with aphasia: methods and resources for training conversation partners. Aphasiology, 1998. 12(9): p. 816-830.

100. Warren, N.M., M.A. Piggott, E.K. Perry, and D.J. Burn, Cholinergic systems in progressive supranuclear palsy. Brain, 2005. 128(Pt 2): p. 239-249.

101. Litvan, I., M. Phipps, V.L. Pharr, M. Hallett, J. Grafman, and A. Salazar, Randomized placebo-controlled trial of donepezil in patients with progressive supranuclear palsy. Neurology, 2001. 57(3): p. 467-73.

102. Kimura, T. and J. Takamatsu, Pilot study of pharmacological treatment for frontotemporal dementia: risk of donepezil treatment for behavioral and psychological symptoms. Geriatr Gerontol Int, 2013. 13(2): p. 506-7.

103. Mendez, M.F., J.S. Shapira, A. McMurtray, and E. Licht, Preliminary findings: behavioral worsening on donepezil in patients with frontotemporal dementia. Am J Geriatr Psychiatry, 2007. 15(1): p. 84-7.

104. Boxer, A.L., D.S. Knopman, D.I. Kaufer, et al., Memantine in patients with frontotemporal lobar degeneration: a multicentre, randomised, double-blind, placebo-controlled trial. Lancet Neurol, 2013. 12(2): p. 149-56.

105. Vercelletto, M., C. Boutoleau-Bretonniere, C. Volteau, et al., Memantine in behavioral variant frontotemporal dementia: negative results. J Alzheimers Dis, 2011. 23(4): p. 749-59.

106. Johnson, N.A., A. Rademaker, S. Weintraub, D. Gitelman, C. Wienecke, and M. Mesulam, Pilot trial of memantine in primary progressive aphasia. Alzheimer Dis Assoc Disord, 2010. 24(3): p. 308 .

107. Gomez-Tortosa, E., R. Rigual, C. Prieto-Jurczynska, et al., Behavioral evolution of progressive semantic aphasia in comparison with nonfluent aphasia. Dement Geriatr Cogn Disord, 2016. 41(1-2): p. 1-8.

108. Rascovsky, K., J.R. Hodges, D. Knopman, et al., Sensitivity of revised diagnostic criteria for the behavioural variant of frontotemporal dementia. Brain, 2011. 134(Pt 9): p. 2456-77.

109. Swartz, J.R., B.L. Miller, I.M. Lesser, and A.L. Darby, Frontotemporal dementia: treatment response to serotonin selective reuptake inhibitors. J Clin Psychiatry, 1997. 58(5): p. 212-6.

110. Yang, Y. and H.P. Schmitt, Frontotemporal dementia: evidence for impairment of ascending serotoninergic but not noradrenergic innervation. Immunocytochemical and quantitative study using a graph method. Acta Neuropathol, 2001. 101(3): p. 256-70.

111. Kales, H.C., L.N. Gitlin, C.G. Lyketsos, Detroit Expert Panel on Assessment and Management of Neuropsychiatric Symptoms of Dementia, Management of neuropsychiatric symptoms of dementia in clinical settings: recommendations from a multidisciplinary expert panel. J Am Geriatr Soc, 2014. 62(4): p. 762-9.
112. O'Connor, C.M., L. Clemson, H. Brodaty, et al., The tailored activity program (TAP) to address behavioral disturbances in frontotemporal dementia: a feasibility and pilot study. Disabil Rehabil, 2019. 41(3): p. 299-310.

113. Gerstenecker, A., K. Duff, B. Mast, I. Litvan, and E.-P.S. Group, Behavioral abnormalities in progressive supranuclear palsy. Psychiatry Res, 2013. 210(3): p. 1205-10.

114. Livingston, G., L. Kelly, E. Lewis-Holmes, et al., Nonpharmacological interventions for agitation in dementia: systematic review of randomised controlled trials. Br J Psychiatry, 2014. 205(6): p. 436-42.

115. Porsteinsson, A.P., L.T. Drye, B.G. Pollock, et al., Effect of citalopram on agitation in Alzheimer disease: the CitAD randomized clinical trial. JAMA, 2014. 311(7): p. 682-91.

116. Schneider, L.S., P.N. Tariot, K.S. Dagerman, et al., Effectiveness of atypical antipsychotic drugs in patients with Alzheimer's disease. N Engl J Med, 2006. 355(15): p. 1525-38.

117. Sorbi, S., J. Hort, T. Erkinjuntti, et al., EFNS-ENS Guidelines on the diagnosis and management of disorders associated with dementia. Eur J Neurol, 2012. 19(9): p. 1159-79.

118. Fujishiro, J., T. Imanishi, K. Onozawa, and M. Tsushima, Comparison of the anticholinergic effects of the serotonergic antidepressants, paroxetine, fluvoxamine and clomipramine. Eur J Pharmacol, 2002. 454(2-3): p. 183-8.

119. Tamai, S. and O.P. Almeida, Nortriptyline for the treatment of depression in progressive supranuclear palsy. J Am Geriatr Soc, 1997. 45(8): p. 1033-4.

120. Newman, G.C., Treatment of progressive supranuclear palsy with tricyclic antidepressants. Neurology, 1985. 35(8): p. 1189-93.

121. Netzel, P.J. and B. Sutor, Electroconvulsive therapy-responsive depression in a patient with progressive supranuclear palsy. $\mathrm{J}$ ECT, 2001. 17(1): p. 68-70.

122. Boeve, B.F., K.A. Josephs, and D.A. Drubach, Current and future management of the corticobasal syndrome and corticobasal degeneration. Handb Clin Neurol, 2008. 89: p. 533-48.

123. Kwok, J.Y.Y., J.C.Y. Kwan, M. Auyeung, et al., Effects of mindfulness yoga vs stretching and resistance training exercises on anxiety and depression for people with Parkinson disease: a randomized clinical trial. JAMA Neurol, 2019. 76(7): p. 755-763.

124. Padala, P.R., K.P. Padala, S.Y. Lensing, et al., Methylphenidate for apathy in community-dwelling older veterans with mild Alzheimer's disease: a double-blind, randomized, placebocontrolled trial. Am J Psychiatry, 2018. 175(2): p. 159-168.

125. Rosenberg, P.B., K.L. Lanctot, L.T. Drye, et al., Safety and efficacy of methylphenidate for apathy in Alzheimer's disease: a randomized, placebo-controlled trial. J Clin Psychiatry, 2013. 74(8): p. 810-6.

126. Herrmann, N., L.S. Rothenburg, S.E. Black, et al., Methylphenidate for the treatment of apathy in Alzheimer disease: prediction of response using dextroamphetamine challenge. J Clin Psychopharmacol, 2008. 28(3): p. 296-301.

127. Oh, J., R.A. Eser, A.J. Ehrenberg, et al., Profound degeneration of wake-promoting neurons in Alzheimer's disease. Alzheimers Dement, 2019. 15(10): p. 1253-1263.

128. Walsh, C.M., L. Ruoff, K. Walker, et al., Sleepless night and day, the plight of progressive supranuclear palsy. Sleep, 2017. 40(11).

129. Sixel-Doring, F., M. Schweitzer, B. Mollenhauer, and C. Trenkwalder, Polysomnographic findings, video-based sleep analysis and sleep perception in progressive supranuclear palsy. Sleep Med, 2009. 10(4): p. 407-15.

130. Yamamoto, T., F. Tateno, R. Sakakibara, et al., Urinary dysfunction in progressive supranuclear palsy compared with other parkinsonian disorders. PLoS One, 2016. 11(2): p. e0149278.

131. Coupland, C.A.C., T. Hill, T. Dening, R. Morriss, M. Moore, and J. Hippisley-Cox, Anticholinergic drug exposure and the risk of dementia: a nested case-control study. JAMA Intern Med, 2019. 
132. Chapple, C.R., R. Martinez-Garcia, L. Selvaggi, et al., A comparison of the efficacy and tolerability of solifenacin succinate and extended release tolterodine at treating overactive bladder syndrome: results of the STAR trial. Eur Urol, 2005. 48(3): p. 464-70.

133. Griebling, T.L., N.L. Campbell, J. Mangel, et al., Effect of mirabegron on cognitive function in elderly patients with overactive bladder: MoCA results from a phase 4 randomized, placebocontrolled study (PILLAR). BMC Geriatr, 2020. 20(1): p. 109.

134. Riedijk, S.R., M.E. De Vugt, H.J. Duivenvoorden, et al., Caregiver burden, health-related quality of life and coping in dementia caregivers: a comparison of frontotemporal dementia and Alzheimer's disease. Dement Geriatr Cogn Disord, 2006. 22(5-6): p. 405-12.

135. Rohs, G., Progressive supranuclear palsy: managing the disabilities and providing nursing support. Axone, 1996. 17(3): p. 60-5.

136. Khanna, M.R., J. Kovalevich, V.M. Lee, J.Q. Trojanowski, and K.R. Brunden, Therapeutic strategies for the treatment of tauopathies: hopes and challenges. Alzheimers Dement, 2016. 12(10): p. 1051-1065.

137. Apetauerova, D., S.A. Scala, R.W. Hamill, et al., CoQ10 in progressive supranuclear palsy: a randomized, placebo-controlled, double-blind trial. Neurol Neuroimmunol Neuroinflamm, 2016. 3(5): p. e266.

138. Bensimon, G., A. Ludolph, Y. Agid, et al., Riluzole treatment, survival and diagnostic criteria in Parkinson plus disorders: the NNIPPS study. Brain, 2009. 132(Pt 1): p. 156-71.

139. Nuebling, G., M. Hensler, S. Paul, A. Zwergal, A. Crispin, and S. Lorenzl, PROSPERA: a randomized, controlled trial evaluating rasagiline in progressive supranuclear palsy. J Neurol, 2016. 263(8): p. 1565-74

140. Leclair-Visonneau, L., T. Rouaud, B. Debilly, et al., Randomized placebo-controlled trial of sodium valproate in progressive supranuclear palsy. Clin Neurol Neurosurg, 2016. 146: p. 35-9.

141. Tolosa, E., I. Litvan, G.U. Hoglinger, et al., A phase 2 trial of the GSK-3 inhibitor tideglusib in progressive supranuclear palsy. Mov Disord, 2014. 29(4): p. 470-8.

142. VandeVrede L, Marian L Dale, Fields S, Frank M, Hare E, Heuer HW, Keith K, Koestler M, Ljubenkov PA, McDermott D, Ohanesian N, Richards J, Rojas JC, Thijssen EH, Walsh C, Wang P, Wolf P, Quinn JF, Tsai R, Boxer AL, Open-label phase 1 futility studies of salsalate and young plasma in progressive supranuclear palsy. Movement Disorders Clinical Practice (in press), 2020.

143. Pharmaceuticals, T., TRX-237 phase 3 clinical trial update. 2016.

144. Boxer, A.L., A.E. Lang, M. Grossman, et al., Davunetide in patients with progressive supranuclear palsy: a randomised, doubleblind, placebo-controlled phase 2/3 trial. Lancet Neurol, 2014. 13(7): p. 676-85.

145. Tsai, R.M., Z. Miller, M. Koestler, et al., Reactions to multiple ascending doses of the microtubule stabilizer TPI-287 in patients with Alzheimer disease, progressive supranuclear palsy, and corticobasal syndrome: a randomized clinical trial. JAMA Neurol, 2019

146. Boxer, A.L., I. Qureshi, M. Ahlijanian, et al., Safety of the taudirected monoclonal antibody BIIB092 in progressive supranuclear palsy: a randomised, placebo-controlled, multiple ascending dose phase $1 \mathrm{~b}$ trial. Lancet Neurol, 2019. 18(6): p. 549-558.

147. West, T., Y. Hu, P.B. Verghese, et al., Preclinical and clinical development of ABBV-8E12, a humanized anti-tau antibody, for treatment of Alzheimer's disease and other tauopathies. J Prev Alzheimers Dis, 2017. 4(4): p. 236-241

148. Beal, M.F., Mitochondrial dysfunction and oxidative damage in Alzheimer's and Parkinson's diseases and coenzyme Q10 as a potential treatment. J Bioenerg Biomembr, 2004. 36(4): p. 381-6.
149. Albers, D.S., R.H. Swerdlow, G. Manfredi, et al., Further evidence for mitochondrial dysfunction in progressive supranuclear palsy. Exp Neurol, 2001. 168(1): p. 196-8.

150. Stamelou, M., A. Reuss, U. Pilatus, et al., Short-term effects of coenzyme Q10 in progressive supranuclear palsy: a randomized, placebo-controlled trial. Mov Disord, 2008. 23(7): p. 942-949.

151. Shoeibi, A. and I. Litvan, Therapeutic options for progressive supranuclear palsy including investigational drugs. Expert Opinion on Orphan Drugs, 2017. 5(7): p. 575-587.

152. Miller, R.G., J.D. Mitchell, M. Lyon, and D.H. Moore, Riluzole for amyotrophic lateral sclerosis (ALS)/motor neuron disease (MND). Cochrane Database Syst Rev, 2007(1): p. CD001447.

153. Naoi, M., W. Maruyama, and K. Inaba-Hasegawa, Revelation in the neuroprotective functions of rasagiline and selegiline: the induction of distinct genes by different mechanisms. Expert Rev Neurother, 2013. 13(6): p. 671-84.

154. Flaherty, D.B., J.P. Soria, H.G. Tomasiewicz, and J.G. Wood, Phosphorylation of human tau protein by microtubule-associated kinases: GSK3beta and cdk5 are key participants. J Neurosci Res, 2000. 62(3): p. 463-72.

155. Forde, J.E. and T.C. Dale, Glycogen synthase kinase 3: a key regulator of cellular fate. Cell Mol Life Sci, 2007. 64(15): p. 1930-44.

156. Noble, W., E. Planel, C. Zehr, et al., Inhibition of glycogen synthase kinase- 3 by lithium correlates with reduced tauopathy and degeneration in vivo. Proc Natl Acad Sci U S A, 2005. 102(19): p. 6990-5.

157. Chen, G., L.D. Huang, Y.M. Jiang, and H.K. Manji, The moodstabilizing agent valproate inhibits the activity of glycogen synthase kinase-3. J Neurochem, 1999. 72(3): p. 1327-30.

158. Martinez, A., M. Alonso, A. Castro, C. Perez, and F.J. Moreno, First non-ATP competitive glycogen synthase kinase 3 beta (GSK-3beta) inhibitors: thiadiazolidinones (TDZD) as potential drugs for the treatment of Alzheimer's disease. J Med Chem, 2002. 45(6): p. 1292-9.

159. Shoeibi, A., N. Olfati, and I. Litvan, Preclinical, phase I, and phase II investigational clinical trials for treatment of progressive supranuclear palsy. Expert Opin Investig Drugs, 2018. 27(4): p. 349-361.

160. Liu, F., K. Iqbal, I. Grundke-Iqbal, G.W. Hart, and C.X. Gong, OGlcNAcylation regulates phosphorylation of tau: a mechanism involved in Alzheimer's disease. Proc Natl Acad Sci U S A, 2004. 101(29): p. 10804-9.

161. Liu, F., J. Shi, H. Tanimukai, et al., Reduced O-GlcNAcylation links lower brain glucose metabolism and tau pathology in Alzheimer's disease. Brain, 2009. 132(Pt 7): p. 1820-32.

162. Smith, S.M., A. Struyk, D. Jonathan, et al., Early clinical results and preclinical validation of the O-GlcNAcase (OGA) inhibitor MK-8719 as a novel therapeutic for the treatment of tauopathies. Alzheimer's \& Dementia: the journal of the Alzheimer's Association 2016. 12(7): p. P261.

163. Therapeutics, A., Alectos Therapeutics announces FDA orphan drug designation for MK-8719: an investigational smallmolecule OGA inhibitor for treatment of progressive supranuclear palsy. 2016.

164. Permanne, B., A. Quattropani, J. Hantson, et al., Pharmacological intervention with the novel o-glcnacase inhibitor ASN-561 reduces pathological tau in transgenic mice. Alzheimer's \& dementia: the journal of the Alzheimer's Association 2015. 11(7): p. P227.

165. Ryan, J.M., A. Quattropani, K. Abd-Elaziz, et al., Phase 1 study in healthy volunteers of the O-glcnacase inhibitor ASN120290 as a novel therapy for progressive supranuclear palsy and related tauopathies. Alzheimer's Dementia 2018. 14(7): p. P251. 
166. Katsimpardi, L., N.K. Litterman, P.A. Schein, et al., Vascular and neurogenic rejuvenation of the aging mouse brain by young systemic factors. Science, 2014. 344(6184): p. 630-4.

167. Villeda, S.A., K.E. Plambeck, J. Middeldorp, et al., Young blood reverses age-related impairments in cognitive function and synaptic plasticity in mice. Nat Med, 2014. 20(6): p. 659-63.

168. Middeldorp, J., B. Lehallier, S.A. Villeda, et al., Preclinical assessment of young blood plasma for Alzheimer disease. JAMA Neurol, 2016. 73(11): p. 1325-1333.

169. Min, S.W., S.H. Cho, Y. Zhou, et al., Acetylation of tau inhibits its degradation and contributes to tauopathy. Neuron, 2010. 67(6): p. 953-66.

170. Min, S.W., X. Chen, T.E. Tracy, et al., Critical role of acetylation in tau-mediated neurodegeneration and cognitive deficits. Nat Med, 2015. 21(10): p. 1154-62.

171. Wischik, C.M., P.C. Edwards, R.Y. Lai, M. Roth, and C.R. Harrington, Selective inhibition of Alzheimer disease-like tau aggregation by phenothiazines. Proc Natl Acad Sci U S A, 1996. 93(20): p. 11213-8.

172. Hochgrafe, K., A. Sydow, D. Matenia, et al., Preventive methylene blue treatment preserves cognition in mice expressing fulllength pro-aggregant human Tau. Acta Neuropathol Commun, 2015. 3: p. 25.

173. Stack, C., S. Jainuddin, C. Elipenahli, et al., Methylene blue upregulates Nrf2/ARE genes and prevents tau-related neurotoxicity. Hum Mol Genet, 2014. 23(14): p. 3716-32.

174. Gauthier, S., H.H. Feldman, L.S. Schneider, et al., Efficacy and safety of tau-aggregation inhibitor therapy in patients with mild or moderate Alzheimer's disease: a randomised, controlled, doubleblind, parallel-arm, phase 3 trial. Lancet, 2016. 388(10062): p. 2873-2884.

175. Medina, M., An Overview on the clinical development of taubased therapeutics. Int J Mol Sci, 2018. 19(4).

176. Gozes, I., M. Bassan, R. Zamostiano, et al., A novel signaling molecule for neuropeptide action: activity-dependent neuroprotective protein. Ann N Y Acad Sci, 1999. 897: p. 125-35.

177. Matsuoka, Y., Y. Jouroukhin, A.J. Gray, et al., A neuronal microtubule-interacting agent, NAPVSIPQ, reduces tau pathology and enhances cognitive function in a mouse model of Alzheimer's disease. J Pharmacol Exp Ther, 2008. 325(1): p. 146-53.

178. Shiryaev, N., Y. Jouroukhin, E. Giladi, et al., NAP protects memory, increases soluble tau and reduces tau hyperphosphorylation in a tauopathy model. Neurobiol Dis, 2009. 34(2): p. 381-8.

179. Rosenmann, H., N. Grigoriadis, D. Karussis, et al., Tauopathy-like abnormalities and neurologic deficits in mice immunized with neuronal tau protein. Arch Neurol, 2006. 63(10): p. 1459-67.

180. Brettschneider, J., K. Del Tredici, V.M. Lee, and J.Q. Trojanowski, Spreading of pathology in neurodegenerative diseases: a focus on human studies. Nat Rev Neurosci, 2015. 16(2): p. 109-20.

181. Kontsekova, E., N. Zilka, B. Kovacech, R. Skrabana, and M. Novak, Identification of structural determinants on tau protein essential for its pathological function: novel therapeutic target for tau immunotherapy in Alzheimer's disease. Alzheimers Res Ther, 2014. 6(4): p. 45.

182. Novak, P., R. Schmidt, E. Kontsekova, et al., FUNDAMANT: an interventional 72-week phase 1 follow-up study of AADvac1, an active immunotherapy against tau protein pathology in Alzheimer's disease. Alzheimers Res Ther, 2018. 10(1): p. 108.

183. Novak, P., R. Schmidt, E. Kontsekova, et al., Safety and immunogenicity of the tau vaccine AADvac1 in patients with
Alzheimer's disease: a randomised, double-blind, placebo-controlled, phase 1 trial. Lancet Neurol, 2017. 16(2): p. 123-134.

184. Bright, J., S. Hussain, V. Dang, et al., Human secreted tau increases amyloid-beta production. Neurobiol Aging, 2015. 36(2): p. 693-709.

185. Yanamandra, K., H. Jiang, T.E. Mahan, et al., Anti-tau antibody reduces insoluble tau and decreases brain atrophy. Ann Clin Transl Neurol, 2015. 2(3): p. 278-88.

186. Yanamandra, K., N. Kfoury, H. Jiang, et al., Anti-tau antibodies that block tau aggregate seeding in vitro markedly decrease pathology and improve cognition vivo. Neuron, 2013. 80(2): p. 402414.

187. Yanamandra, K., T.K. Patel, H. Jiang, et al., Anti-tau antibody administration increases plasma tau in transgenic mice and patients with tauopathy. Sci Transl Med, 2017. 9(386):eaal2029.

188. Courade, J.P., R. Angers, G. Mairet-Coello, et al., Epitope determines efficacy of therapeutic anti-Tau antibodies in a functional assay with human Alzheimer Tau. Acta Neuropathol, 2018. 136(5): p. 729-745.

189. Morris, M., P. Hamto, A. Adame, N. Devidze, E. Masliah, and L. Mucke, Age-appropriate cognition and subtle dopamineindependent motor deficits in aged tau knockout mice. Neurobiol Aging, 2013. 34(6): p. 1523-9.

190. Adwan, L., G.M. Subaiea, R. Basha, and N.H. Zawia, Tolfenamic acid reduces tau and CDK5 levels: implications for dementia and tauopathies. J Neurochem, 2015. 133(2): p. 266-72.

191. Finkel, R.S., E. Mercuri, B.T. Darras, et al., Nusinersen versus sham control in infantile-onset spinal muscular atrophy. N Engl J Med, 2017. 377(18): p. 1723-1732.

192. Ionis Pharmaceuticals, I., IONIS-HTT Rx (RG6042) Top-line data demonstrate significant reductions of disease-causing mutant huntingtin protein in people with Huntington's disease. 2018.

193. DeVos, S.L., R.L. Miller, K.M. Schoch, et al., Tau reduction prevents neuronal loss and reverses pathological tau deposition and seeding in mice with tauopathy. Sci Transl Med, 2017. 9(374): eaag0481.

194. Boxer, A.L., J.T. Yu, L.I. Golbe, I. Litvan, A.E. Lang, and G.U. Hoglinger, Advances in progressive supranuclear palsy: new diagnostic criteria, biomarkers, and therapeutic approaches. Lancet Neurol, 2017. 16(7): p. 552-563.

195. Golbe, L.I. and P.A. Ohman-Strickland, A clinical rating scale for progressive supranuclear palsy. Brain, 2007. 130(Pt 6): p. 155265.

196. Bang, J., I.V. Lobach, A.E. Lang, et al., Predicting disease progression in progressive supranuclear palsy in multicenter clinical trials. Parkinsonism Relat Disord, 2016. 28: p. 41-48.

197. Duff, K., D. McDermott, D. Luong, C. Randolph, and A.L. Boxer, Cognitive deficits in progressive supranuclear palsy on the Repeatable Battery for the Assessment of Neuropsychological Status. J Clin Exp Neuropsychol, 2019. 41(5): p. 469-475.

198. Rojas, J.C., J. Bang, I.V. Lobach, et al., CSF neurofilament light chain and phosphorylated tau 181 predict disease progression in PSP. Neurology, 2018. 90(4): p. e273-e281.

199. Tsai, R.M., A. Bejanin, O. Lesman-Segev, et al., (18)F-flortaucipir (AV-1451) tau PET in frontotemporal dementia syndromes. Alzheimers Res Ther, 2019. 11(1): p. 13.

Publisher's Note Springer Nature remains neutral with regard to jurisdictional claims in published maps and institutional affiliations. 